\title{
Hypothetical Immunological and Immunogenetic Model of Heterogenous Effects of BCG Vaccination in SARS-CoV-2 Infections: BCG-induced Trained and Heterologous Immunity
}

\section{Dženan Kovačić}

International Burch University, Faculty of Engineering and Natural Sciences, Department of Genetics and Bioengineering, Sarajevo, Bosnia and Herzegovina; Sharklab ADRIA: Center for marine and frewater biology, Triq il-Kappella Tal-Lunzjata, In-Naxxar, Malta Corresponding author: dzenan.kovacic@stu.ibu.edu.ba

(iD) https://orcid.org/0000-0003-3218-5073

\section{Andrej A. Gajić}

Shark Tales, Funded by the National Geographic Society, Washington, D.C., USA; Sharklab ADRIA: Center for marine and frewater biology, Triq il-Kappella Tal-Lunzjata, In-Naxxar, Malta

(D) https://orcid.org/0000-0001-5138-9368

\section{Dado Latinović}

International Burch University, Faculty of Engineering and Natural Sciences, Department of Genetics and Bioengineering, Sarajevo, Bosnia and Herzegovina (iD) -

\section{Adna Softić}

International Burch University, Faculty of Engineering and Natural Sciences, Department of Genetics and Bioengineering, Sarajevo, Bosnia and Herzegovina

(iD) https://orcid.org/0000-0002-4405-2916
DOI: https://doi.org/10.20883/medical.e551

Keywords: immunogenetics, immunology, trained immunity, heterologous immunity, BCG trained immunity, TLR signalling, COVID-19 and BCG

Published: 2021-12-29

How to Cite: Kovačić D, Gajić AA, Latinović D, Softić A. Hypothetical Immunological and Immunogenetic Model of Heterogenous Effects of BCG Vaccination in SARS-CoV-2 Infections: BCG-induced Trained and Heterologous Immunity. Journal of Medical Science. 2021;90(4);e551. doi:10.20883/ medical.e551.

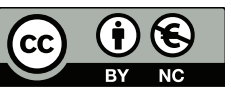

(c) 2021 by the author(s). This is an open access article distributed under the terms and conditions of the Creative Commons Attribution (CC BY-NC) licencse. Published by Poznan University of Medical Sciences

\begin{abstract}
Though SARS-CoV-2 infections are yet to be completely characterised in a host-pathogen interaction context, some of the mechanisms governing the interaction between the novel betacoronavirus and the human host, have been brought to light in satisfactory detail. Among the emerging evidence, postulates regarding potential benefits of innate immune memory and heterologous immunity have been put under discussion. Innate immune memory entails epigenetic reprogramming of innate immune cells caused by vaccination or infections, whereas heterologous immunity denotes cross-reactivity of T cells with unrelated epitopes and bystander CD8+ activation. Familiarization of the host immune system with a certain pathogen, educates monocytes, macrophages and other innate cells into phenotypes competent for combating unrelated pathogens. Indeed, the resolution at which non-specific innate immune memory occurs, is predominant at the level of enhanced cytokine secretion as a result of epigenetic alterations. One vaccine whose non-specific effects have been documented and harnessed in treating infections, cancer and autoimmunity, is the Bacillus Calmette-Guérin (BCG) vaccine currently used for immunization against pulmonary tuberculosis (TB). The BCG vaccine induces a diverse cytokine secretion profile in immunized subjects, which in turn may stimulate epigenetic changes mediated by immunoreceptor signalling. Herein, we provide a concise summarization of previous findings regarding the effects of the BCG vaccine on innate immune memory and heterolo-
\end{abstract}


gous immunity, supplemented with clinical evidence of the non-specific effects of this vaccine on non-mycobacterial infections, cancer and autoimmunity. This interpretative synthesis aims at providing a plausible immunological and immunogenetic model by which BCG vaccination may, in fact, be beneficial for the current efforts in combating COVID-19.

\section{Background}

The COVID-19 pandemic is a rapidly evolving situation, with novel information emerging from the academic ether on a daily basis. Though the immunobiological details of SARS-CoV-2 infections continue to be uncovered in a rapid rate, a modest number of mechanisms governing the interaction between the novel betacoronavirus, have been brought to light at a satisfactory level of detail. Among the evidence that has emerged since the onset of the pandemic, postulates regarding the potential benefit of innate immune memory and heterologous immunity have been put forth and continue to be discussed. Innate immune memory entails epigenetic reprogramming of innate immune cells caused by vaccination, or viral and bacterial infections, whereas heterologous immunity colloquially denotes crossreactivity of $T$ cells with unrelated epitopes, along with bystander $\mathrm{CD}^{+}$activation [1]-[11]. On the innate level, familiarization of the host immune system with a certain pathogen, may educate monocytes, macrophages and other innate cells into becoming more competent in combating non-related bacterial or viral pathogens [10], [12]. Interestingly, however, $T$ cell cross reactivity likely stems from host genetic factors rather than pathogen-induced epigenetic reprogramming [13]-[19]. Indeed, the resolution at which bacteria, viruses and vaccines confer non-specific effects that lead to innate immune memory, is likely at the level of enhanced cytokine secretion as a result of epigenetic alterations [5], [9], [10], [20]-[27]. One vaccine whose non-specific effects have been documented and harnessed in treating infections, cancer and autoimmunity, is the Bacillus Calmette-Guérin (BCG) vaccine currently used for immunization against pulmonary tuberculosis (TB). The BCG vaccine induces a diverse cytokine secretion profile in immunized subjects, which in turn may stimulate potentially beneficial epigenetic changes mediated by immunorecep- tor signalling [8], [28]-[31]. Additionally, the phenomenon of heterologous immunity has not only been observed in cases of BCG vaccination. The influenza vaccine may confer varying degrees of protection against severe forms of COVID19 disease and presumably SARS-CoV-2 infection. This is reflected in studies where patients receiving the influenza vaccine within 120 days of a positive diagnosis were at a reduced risk of post-COVID-19 complications, further coupled with a decreased rate of COVID-19 positive cases among vaccinated populations [32]-[34]. However, much like in the case of BCG vaccination, more work is required to derive a definitive conclusion. Unsurprisingly, in a recently published preprint by Föhse et al. it was reported that the COVID-19 BNT162b2 mRNA vaccine likely induces complex innate immune system reprogramming at the level of cytokine regulation, offering protection against unrelated bacterial, fungal and viral stimuli [35].

A correlation between reduced COVID-19 morbidity and universal BCG vaccination has been implied since the early stages of the pandemic, though the immunobiological background and potential clinical significance of this remains to be substantiated [36]. Indeed, BCG vaccination leads to cellular memory at the level of both cytokines and cytokine-related transcription factors, some of which have been identified as potential targets of SARS-CoV-2 in order for the virus to establish immunosuppression [37]-[40]. The importance of this is reflected in the fact that SARS-CoV-2 dampens the adaptive immune response by acting directly on the transcriptional machinery of innate immune cells. Considering that the BCG vaccine leads to epigenetic changes that may be beneficial in preventing SARS-CoV2-mediated immunosuppression or dissemination, this issue must be addressed in a methodical way that draws back to basic immunobiology, rather than mere statistical epidemiology. Herein, we provide a concise summarization of previous findings regarding the effects of the BCG vaccine 
on innate immune memory and heterologous immunity, supplemented with clinical evidence of the non-specific effects of this vaccine on nonmycobacterial infections, cancer and autoimmunity. This interpretative synthesis aims at providing a plausible and unbiased immunological and immunogenetic model by which BCG vaccination may, in fact, be beneficial for the current efforts in combating COVID-19.

\section{Cellular Entry of SARS-CoV-2}

SARS-CoV-2 infections share similarities with the Middle East Respiratory Syndrome (MERS)$\mathrm{CoV}$ and Severe Acute Respiratory Syndrome (SARS)-CoV in their mode of interaction with the human host. There is significant receptor binding domain (RBD) similarity between SARS-CoV and SARS-CoV-2 found on the spike

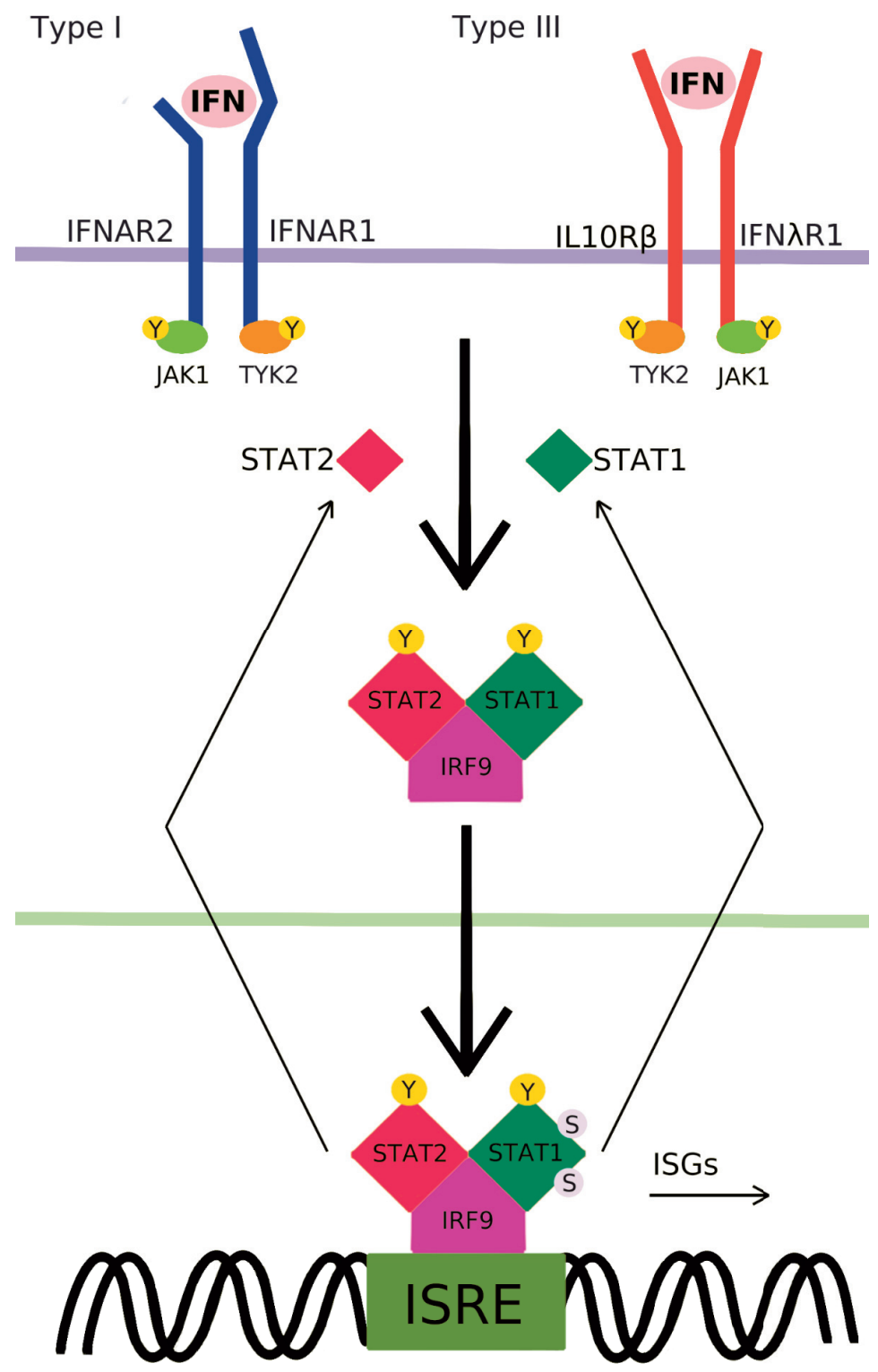

Figure 1. Type I and type III interferon responses are pivotal in the human innate antiviral response. Canonically, type I IFN signalling eventuates in the activation of the Janus kinase (JAK) and signal transducer and activator of transcription (STAT) 2 proteins, whereas type III IFN responses recruits STAT1. Interferon regulatory factor (IRF) 9, particularly relevant in the antiviral response, associates with the JAK-STAT dimer, thereby creating the IRF9 transcription factor. IRF9 transcription factor is translocated into the nucleus, upon which it binds to the interferon stimulated response element (ISRE) located upstream of the interferon stimulated genes (ISG) 
(S) protein of both viruses [41], [42]. SARS-CoV and SARS-CoV-2 infect cells expressing angiotensin converting enzyme 2 (ACE2), located in the lungs, the gastrointestinal tract, the renal tract and the heart [41], [43]-[45]. SARS-CoV-2, however, has overall higher binding affinity for ACE2 than SARS-CoV, and this is particularly pronounced for several clinically-relevant variants [39], [46], [47]. Once the S protein is bound to ACE2, ADAM metallopeptidase domain 17 (ADAM 17) and other sheddases cleave the extracellular domain as a method of preventing cellular entry. ADAM 17 further processes the membrane form of the interleukin (IL)- 6 receptor (IL-6R)- $a$ into a soluble form that will confer activation of signal transducer and activator of transcription 3 (STAT3) in non-immune cells, under the mediation of gp130. STAT3, in turn, activates the nuclear factor kappa-light-chainenhancer of activated B cells (NF-KB) pathway, leading to potentially detrimental inflammatory responses [48].

It is possible that SARS-CoV-2, like MERSCoV and SARS-CoV, binds to non-ACE2 receptors through carbohydrate binding, specifically various lectins and different glycoconjugates of different bacterial strains that comprise the lung microbiota [49]. Such findings offer clues for the immunosuppressive capabilities of SARS-CoV-2, particularly when discussing the notion that the viral RBD domain binds to C-type lectins such as CD209/DC-SIGN and CD209/L-SIGN, which would presumably allow the virus to infect innate and adaptive immune cells [38], [50], [51].

\section{Immune Response to SARS-CoV-2}

Innate Immune Response

Upon entry of the virus into the cell, cytosolic recognition of RNA viruses by innate immune cells occurs at the interface between the viral RNA or replication intermediates and the innate cytosolic RNA sensor, toll-like receptor (TLR) 3 and TLR7 and the cytosolic dsRNA sensor retinoic acidinducible gene (RIG) I/ melanoma differentiation-associated protein (MDA) 5 [52]. Production of type I interferon (IFN) is triggered when viral pathogen-associated molecular patterns (PAMPs) are recognized by these receptors, activating NF-KB and interleukin regulatory factor (IRF)
3 , which are then translocated into the nucleus to initiate transcription of pro-inflammatory cytokine genes, including IFN type I [53]. Successful secretion of IFN in the cytosol triggers the Janus kinase (JAK) - signal transducer and activator of transcription (STAT) 1 pathway, through the interferon- $\alpha / \beta$ receptor (IFNAR) (Figure 1 ) [53]. Although the role of DCs, and particularly resident respiratory DCs (rDCs) in SARS-CoV-2 infections warrants further research, the clinical presentation of COVID-19 is likely in part owed to altered DC function, thereby preventing their migration to the mediastinal and cervical lymph nodes in order to prime virus-specific $T$ cells [54], [55]. Per contra, impaired rDC migration has been correlated with age, thereby offering another plausible explanation, or at least a relevant factor, to the discussion COVID-19 risk groups [55]. Since SARS-CoV-2 is particularly efficient at avoiding IFN-mediated innate immunity, this leads to massive immunopathology or extensive viral replication in the lungs and the respiratory tract, thereby often warranting a need for patient hospitalization in the confines of intensive care.

\section{Adaptive Immunity in COVID-19}

The issue of SARS-CoV-2 adaptive immunity, specifically protection longevity and its correlation to emerging viral variants, continues to be investigated and awaits definitive conclusions. Though certain studies have reported antibody longevity supported by long-lived bone marrow plasma cells (BMPCs), some evidence suggests that the neutralizing capability of these antibodies for SARS-Cov-2 variants is rendered unsatisfactory over time, at least for the $S$ protein [56][58]. This is supported by studies reporting reinfections with genomically distinct SARS-Cov-2 variants [59], [60].

Secretion of cytokines and antigen presentation by antigen presenting cells (APCs) helps prime and direct the adaptive immune response to infections [61]. The Th1 immune response is the key player in response to viral agents, and was shown to be particularly relevant for resolving infections with SARS-CoV and MERS-CoV and, unsurprisingly, SARS-COV-2 [52], [62]. In the case of SARS-CoV infections, the specificity of $B$ and $T$ cell epitopes were mapped to the $M, N, E$ and $S$ viral proteins [63]. For SARS-Cov-2, however, these epitopes have thus far been mapped 
to non-structural proteins (nsps), particularly nsp3, nsp5, the nucleocapsid ( $\mathrm{N}$ ) protein, the $\mathrm{S}$ protein and the open reading frame (ORF) 3a [64]. Interestingly, an IgM response targeting nsp3 and nsp5 have been correlated with a better prognosis of COVID-19, whereupon an IgG targeting $S$, $\mathrm{N}$ and ORF3a are associated with mortality and increased severity [64]. Namely, the serum of COVID-19 patients shows moderate cross-reactivity with SARS-CoV and no reactivity for other coronaviruses [65]. In terms of seroconversion, Zhao et al. found that, among 173 patients whose samples were analysed, seroconversion time for $\mathrm{Ab}, \mathrm{IgM}$ and $\mathrm{IgG}$ was $93.1 \%$ (161/173), $82.7 \%$ (143/173) and $64.7 \%(112 / 173)$ respectively . Specifically, antibody presence was determined to be $<40 \%$; however, after day 15 , this significantly changed to $100.0 \%, 94.3 \%$ and $79.8 \%$ for $\mathrm{Ab}$, IgM and IgG respectively, and relatively similar results were obtained in other studies [66]-[69]. Interestingly, long lasting IgG and neutralizing antibodies have been reported even 2 years upon initial diagnosis with SARS-CoV, and there is encouraging evidence that the same may be true for SARSCoV-2 [70]. As evidence continues to emerge, it will be interesting to see whether the aforementioned long-lasting neutralizing antibodies following SARS-Cov-2 infection will carry sufficiently broad specificity for emerging variants in terms of the $\mathrm{S}$ protein and other immunogenic viral proteins.

Increase in serum Th2 cytokines were detected SARS-CoV, along with a higher frequency of polyfunctional $\mathrm{CD}^{+} \mathrm{T}$ cells secreting tumour necrosis factor (TNF) $a$, IFN- $y$ and IL-2 in severely ill SARS-CoV patients; an overall increase in serum Th2 cytokines were present in patients that faced a fatal outcome [71]. However, it should be noted that $\mathrm{CD}^{+}$cells dominate over $\mathrm{CD}^{+}$in SARS-CoV, and strongly neutralizing Abs are present in convalescent patients [71]. As one may infer from the herein presented immunological data, severe lung immunopathology occurs at the delicate interface between the Th1 and Th2 immune response, yet commences at the level of innate immunity. Reducing IFN-mediated infection control allows SARS-CoV-2 to evade immune defences and delay the onset of adaptive immunity, which later results in rampant inflammation that damages the protective epithelial alveolar tissue comprised of ACE2-expressing type
II alveolar cells [72], thus leaving the pulmonary tissue vulnerable to development of bacterial pneumonia [65]. Patients void of certain medical conditions generally fare better than those who are immunocompromised or who have previously been diagnosed with a condition that may be detrimental for competently combating viral infections [43].

\section{Immune Evasion Tactics of SARS-CoV-2}

SARS-CoV dampens the JAK-STAT pathway, which seems to be mechanism likely utilized by SARS-CoV-2 for immune evasion [52], [53]. This results in delayed onset of the INF-mediated anti-viral response by way of underexpression of genes containing interferon stimulated response element (ISRE), which has thus far been supported by in vivo and ex vivo studies on SARS-CoV and MERS-CoV [73]-[75]. SARS-CoV successfully interferes with induction with type I IFN by interfering with downstream signalling of cytosolic RNA sensors, through ubiquitination and subsequent degradation of their adaptor molecules, or by inhibiting the translocation of IRF3 into the nucleus by way of non-structural proteins PLpro and ORF3b [53], [76], [77]. Expressed both by MERS-CoV and SARS-CoV, PLpro has also been shown to inhibit dissociation of NF-KB from $\mathrm{I}-\mathrm{KB}$, which in turn inhibits the proper functioning NF- $\mathrm{KB}$ transcription factor [78]. By reducing the host's ability to control the infection, SARSCoV-2 is able to freely replicate within the infected cell, and the mechanisms by which these evasion tactics eventuate leads to extensive inflammatory immunopathology. The reduced IFN-mediated viral control paves the way for viremia, as suppression of type I and III interferons leads to insufficient expression of interferon stimulated (ISG) genes [43]. These findings are in favour of the hypothesized pathogenesis discussed by Lin et al., who made the observation that acute respiratory distress syndrome (ARDS) is initiated somewhere around day 8 of disease onset, likely due to the overwhelming increase in pro-inflammatory cytokines, neutrophils and other immune cells which cause detrimental inflammatory damage to the host when excessively recruited [43]. Further supporting this hypothesis are data from 
138 hospitalized COVID-19, where an increase in neutrophils, proinflammatory cytokines, D-Dimer and lymphopenia were detected in severely ill or deceased patients, contrasted with those who successfully recovered [79].

Dysregulation of functional T cells is particularly pronounced in SARS-CoV and likely SARSCoV-2 infections, leading to overexpression of the programmed cell-death protein (PD)-1, $T$ cell immunoglobulin and mucin domain-containing protein 3 (TIM-3) and T cell immunoreceptor with Ig and ITIM domains (TIGIT), as a consequence of excess production of IL-6, IL- 6 and TNF-a [80]-[83]. Inducing overexpression of the aforementioned proteins is a sensical approach for SARS-CoV-2 to take. After all, even when minutely expressed on the surface of $T$ cells, PD-1 negatively regulates $T$ cell activity and sees elevated expression in exhausted $T$ cells [84]. Furthermore, hierarchical T cell loss, along with $\mathrm{T}$ cell suppression and dysfunction are mediated by high expression levels of TIM-3 via impedance of cytokine production, particularly TNF and IFN-y [85]. Expressed as a coinhibitory receptor on natural killer (NK) cells, memory $T$ cells, follicular Th cells, and on a subset of regulatory $T$ cells (Tregs), TIGIT engagement leads to inhibition of Th1 and Th17 cell response [86]-[90]. TIGIT ligation has been shown to directly suppress $\mathrm{T}$ cell proliferation and cytokine production of $\mathrm{CD}^{4+} \mathrm{T}$ cells. Furthermore, TIGIT may indirectly inhibit T cell response through CD155 in DCs, leading to the production of the immunosuppressive cytokine IL-10 [90]. Though substantial work stands in the way of more comprehensive understanding, it is clear that SARS-CoV-2 likely utilizes similar immune evasion mechanisms as MERS-CoV and SARS-CoV in order to circumvent the human immune system.

\section{The Bacillus Calmette-Guérin Vaccine}

\section{The Adaptive and Innate Immune Response to BCG Immunization}

Despite it being the only approved vaccine for $\mathrm{TB}$, the protection it offers is quite heterogenous in adults and adolescents $(0-80 \%)$ [91]. This includes heterogenous efficacy in the context of its initial purpose, which is prevention of dis- seminated $T B$, tuberculous meningitis and severe forms of TB in children, where factors such as geographical location influence vaccine efficacy, though neonatal and postnatal administration of the vaccine offers decent protection against paediatric cases of disseminated TB and meningitis $(60-80 \%)$ [92]-[94]. In spite of this, the current consensus is that there is an urgent need for a novel TB vaccine [95]. Even the induced cytokine profiles vary across populations. Evidence of the benefits of re-vaccination is relatively scarce and inconclusive, although it has been postulated that it does induce cellular and humoral immunity to an unclear extent [11], [91], [96], [97]. Administration routes may also play a role in the varying efficacy and limited protection [93]. Though most studies regarding discrepancies between BCG administration routes and their effects on efficacy stem from animal models, certain human studies have shed light on how different strains elicit distinct immune responses [98], [99]. This is reflected in differences between efficacy in the induction of specific IgG and IgA against various mycobacterial components such as lipoarabinomannan (LAM). The intranasal administration of BCG induces increased production of specific and non-specific IgG and IgA through IL-17 in mice [100], [101]. Studies on Rhesus monkeys and guinea pigs found that aerosol BCG administration increased protection to virulent $M$. tuberculosis challenge, although antibody production was never measured in human aerosol BCG studies [102]. Interestingly, an NHP-based study on intravenous (IV) BCG injections [103], revealed strikingly improved protection and precipitating antibodies post-vaccination, namely $\lg G, \lg M$ and IgA. Currently the specific protective implications of these findings warrant further research, however such striking findings are native to IV BCG injections alone [91], [104]. Efficacy of the BCG vaccine presumably varies accordingly to the virulence of the BCG strain, however there is no sufficient data that clearly elucidates the true depth of the immunogenicity of different strains and how it confers protective immunity and nonspecific effects [91], [105], [106].

Another layer of complexity is added to the topic of BCG strains by the presence of environmental mycobacteria that humans are exposed to in varying degrees across different geographies [107]-[110]. Limited data is available on the 
antigens related to environmental mycobacteria, thus making the differentiation between different $\mathrm{T}$-cell responses and various environmental mycobacteria, increasingly difficult, particularly in the context of BCG [93]. However, different B cell epitopes for different BCG strains were proposed as the plausible cause of heterogenous efficacy [111]. It should be noted that the overall topic of the humoral response to BCG vaccination has been modestly investigated. Regardless, the scarcity of comprehensive studies on this particular topic does not rule out the potentially significant effects that BCG vaccination has on humoral immunity.

Innate immune memory is not a novel concept, and has been previously explored to varying degrees of success in the context of BCG and other pathogens. Immunological memory of innate immune cells, though in defiance of the dogmatic classification of the innate immune system as void of permanent memory, has been compellingly challenged in recent years. It is known that exposure to PAMPs leads to improved innate immune response to bacterial and viral infections, though the underlying mechanisms behind this are poorly understood [6], [7]. Interactions between cell surface receptors of innate immune cells and their agonists, appear to be the driving force of these long-lived cellular memory. Despite there not being a comprehensive map displaying the ways in which BCG confers innate immune memory, numerous studies have validated the assumptions that BCG may effectively be used in non-mycobacterial infections for therapeutic purposes. Interestingly, BCG-induced training of the innate immune system seems to be completely independent of B and T cells.

Upon administration of the vaccine via intradermal injection, a pro-inflammatory response is elicited at the injection site, which includes IL-1 $\beta$, TNFa, monocyte chemoattractant protein-1 (MCP-1/CCL2), and IL-8, the source of which are local innate immune cells [112], [113]. Stimulation of monocytes/macrophages with these and other cytokines have been correlated with trained immunity. Interestingly, BCG-enhanced IL-1 $\beta$ production has been strongly correlated with human trained immunity that offers protection against the Yellow fever Virus (YFV) [114], [115]. Innate immune cells migrate to the injection site around day 9 post-vaccination. Adult humans that have been BCG vaccinated for the first time have lingering BCG at the injection site for approximately 4 weeks, eventuating in a cellular infiltrate comprised of mostly of $\mathrm{CD} 15^{+}$neutrophils, although $\mathrm{CD}^{+}$lymphocytes and $\mathrm{CD}^{+} 4^{+}$monocytes may also be found [93], [106], [116]. Migration of APCs carrying live mycobacteria or mycobacterial antigens to proximal lymph nodes, under the mediation of type I polarizing cytokines and IFN-Y, results in education of naïve T-cells into $C D 4^{+}$ and $C D^{8+}$ cells [107], [117], [118]. Presence of IFN-Y further propagates antimycobacterial activity of macrophages and mediates enhanced antibody production by plasma cells [119], [120]. A pool of mycobacteria-specific $C^{8+}$ cells that secrete IFN- $\gamma$ and express granzymes and perforins, are detectable in peripheral blood up to 10 weeks post-vaccination in human newborns [121], [122]. Furthermore, large amounts of TNF-a, IL-2 and IFN-y are produced by Th1 $\mathrm{CD} 4^{+}$cells, which were also detectable in ex vivo studies investigating BCG-immunized newborns [123]-[125]. Enhancement of the T-cell response to BCG administration is conferred by neutrophils ingesting live BCG [126], [127]. Although macrophages, NK cells and monocytes have been given the most attention in studies regarding innate immune memory, DCs may also garner phenotypic changes that favour long-lived immunological memory [128], [129]. 4-8 weeks upon BCG immunization, a longlived $B$ cell response is induced, eventuating in an increase in secretion of IgG [119], [130] .

\section{A Model of Innate Immune Memory}

Epigenetic Modifications of Cellular Memory and Response Genes in Innate Phagocytic Cells: TLR Signalling

Exposure to the mannose-capped lipoarabinomannan (ManLAM) found on the cell walls of $M$. tuberculosis, BCG and other mycobacteria, promote IL-8 secretion specifically by macrophages, which further stimulates recruitment and activation of neutrophils [27], [131]-[134]. However, other BCG molecular patterns may also be involved. Stimulated neutrophils prime macrophages into phenotypes that confer protection against a wide variety of pathogens, and such phenotypes demonstrate longevity both upon BCG vaccination and stimulation by non-mycobacterial PAMPs [112], [113], [134]. The root of this longevity may 
indeed be found in the epigenetic reprograming of innate immune cells, as such phenotypes evidently extend towards myeloid progenitor cells, with TLR signalling being heavily implicated in the process [24].

Generally, TLR-associated macrophage inflammatory genes may be differentiated into primary response genes (PRGs) and secondary response genes (SRGs), with PRGs being induced within approximately one hour upon stimulation [24]. TLR ligation confers permissive chromatin regions as a result of histone $\mathrm{H} 3$ lysine residue 4 trimethylation $(\mathrm{H} 3 \mathrm{~K} 4 \mathrm{me} 3)$ and $\mathrm{H} 3$ acetylation (H3A) (Figure 2) [24]. Such epigenetic modifications lead to transcriptionally engaged RNA polymerase II (RNA pol. II) being bound to the promoter proximal regions of stimulus-responsive PRG, even after stimulus-induced signalling. Under homeostatic conditions, certain PRGs have higher basal transcriptional activity even in the absence of stimulus due to higher levels of $\mathrm{H} 3 \mathrm{~K} 4 \mathrm{me} 3$ within their transcription start sites (TSS) [24]. Of course, TLR signalling enhances the transcriptional activity of such genes. These basal epigenetic modifications have been heavily correlated with the binding of the specificity protein (Sp1) transcription factor to GC-abundant $\mathrm{CpG}$ elements found within the PRG promoters [23], [113].
An emphasis to extend of this epigenetic programming, are findings pertaining to the presence of protective BCG-trained monocytes 3 months following vaccination, and the underlying mechanism was associated with $\mathrm{H} 3 \mathrm{~K} 4 \mathrm{me} 3$ and $\mathrm{H} 3 \mathrm{~A}$ on promoters associated with PRG [22]. BCG vaccination significantly increases trimethylation of PRG promoters by way of TLR4 and IFN-y-mediated signalling in macrophages, though other TLRs are very likely involved at least on a monocyte differentiation level [135]. Considering that monocytes express each type of TLR, BCG vaccination could induce their epigenetic reprogramming via TLR signalling, thereby causing their differentiation into phenotypes of trained immunity [136]. These phenotypes may show increased potency for the clearance of viral infections, as the aforementioned cells are the first ones to encounter viral and bacterial pathogens.

\section{Interferons and Epigenetic Modification of Interferon-stimulated Genes}

BCG vaccination induces an IFN- $\gamma$ response through stimulation with numerous mycobacterial antigens [28], [93]. Though BCG-induced innate immune cell memory phenotypes are increasingly studied in the context of protection against bacteria and fungi, it may render the innate immune system better equipped for viral infections with
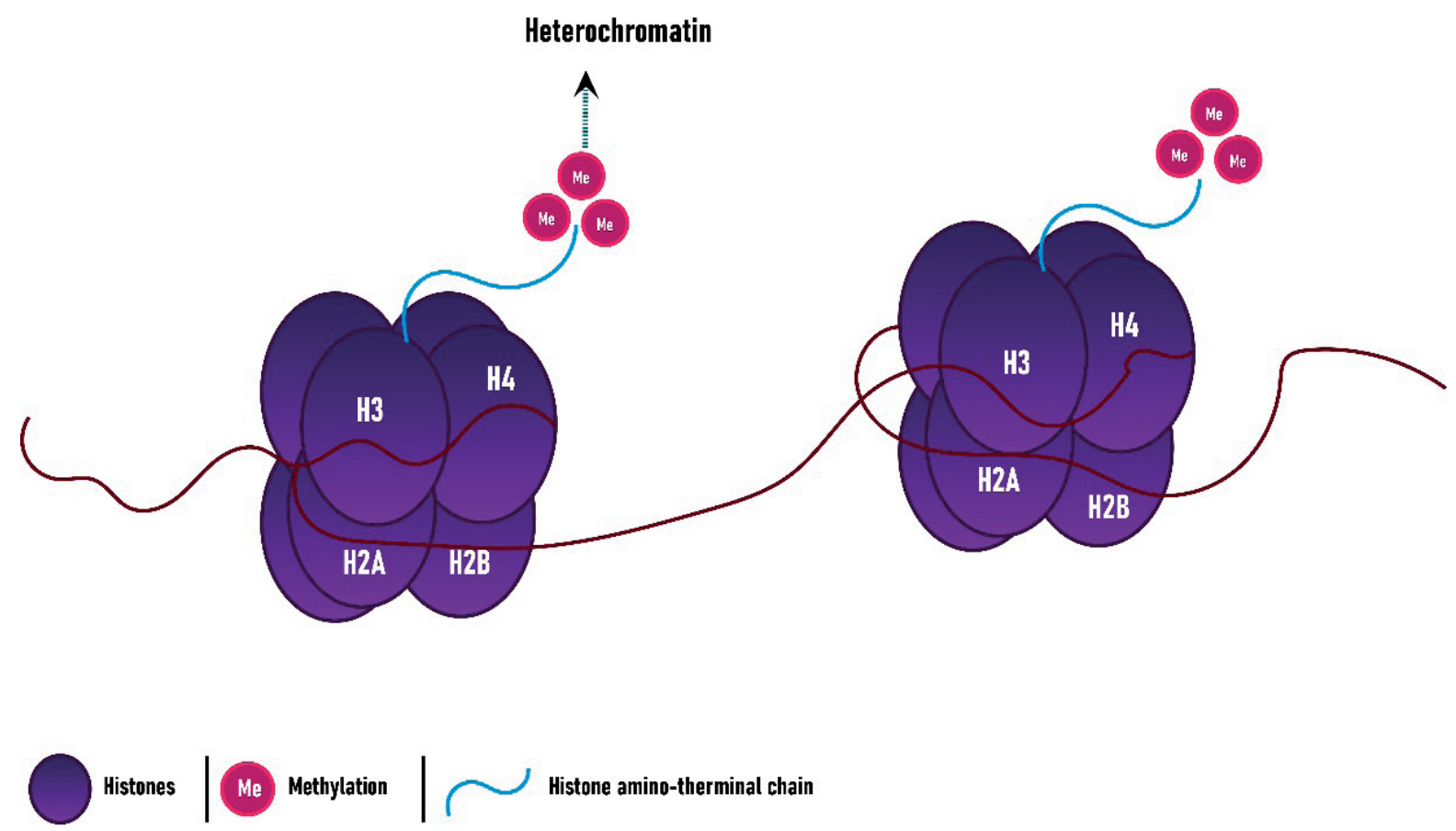

Figure 2. Histone $\mathrm{H} 3$ trimethylation at lysine residue 4 at promoter-associated GC-abundant $\mathrm{CpG}$ elements, is an epigenetic modification associated with trained immunity 
RNA viruses such as SARS-CoV-2. Epigenetic modifications committed to cellular memory upon IFN exposure open some interesting questions with regards to SARS-CoV-2 immune evasion tactics, the answers to which are gradually emerging. BCG vaccination leads to increased production of IFNs, such as IFN- $\beta$ and IFN- $\gamma$, therefore creating optimal conditions for epigenetic modifications [25], [26], [137], [138]. Whether this holds any merit for COVID-19 prophylaxis or treatment remains to be determined.

The relevance of type I and II IFN in antiviral response has been fastidiously substantiated, thereby making these IFN classes integral in the discussion of SARS-CoV-2 immunopathology [26]. IFN stimulation of macrophages eventuates in the creation of chromatin marks for transcriptional memory via histone trimethylation of histone H3.3 and H3K36me3 [113]. The ISGs that take part in macrophage cellular memory have been thoroughly studied, though distinct sets of genes of other innate immune cells may undergo similar modification when adequately stimulated. Interestingly, IFN memory evidently depends on functional STAT1, whereas STAT3 appears to be redundant for induction of IFN memory phenotypes [26]. Contextually to innate immune memory, ISGs may be divided into refractory (108), memory (66) and non-memory (251) ISGs, and this was elegantly demonstrated by Kamada and others in their work on IFN-induced macrophage memory [26]. Marks of permissive chromatin are most prominent in the memory-associated genes, with increased RNA pol. II binding status in contrast to refractory and non-memory ISGs [139]. Though BCG vaccination induces IFN- $\gamma$, thereby conferring epigenetic modifications of ISGs, it is likely that this represents only a component of innate immune memory, rather than the underlying mechanism.

\section{BCG-induced Epigenetic Modifications Through NOD2 Signalling}

BCG-induced trained immunity likely depends on a large number of host-specific, environmental and vaccine-related factors, with modest progress in identifying PAMPs that promote epigenetic modifications (Figure 3 ). Progress made in recent years, however, points to host receptors playing a particularly relevant role in acquiring phenotypic traits of trained immunity, coupled with a miniscule number of identified antigens. For instance, muramyl dipeptide (MDP) found in mycobacteria, including BCG, has been shown to confer viral protection in a nucleotide-binding oligomerization domain-containing protein 2 (NOD2) and IFN- $\beta$-mediated fashion [37], [140]. MDP treatment of cell lines before or after infection induces NF-KB and mitogen-activated protein kinase (MAPK) cascades, with potential relevance with immunosuppressive infections with pathogens such as SARS-CoV-2 [139], [141]. In fact, in vitro pre-treatment of fibroblasts with MDP leads to human cytomegalovirus (HCMV) suppression upon NOD2 ligation; an outcome that is IFN- $\beta$ dependent and suggestive of the relevance of NOD2 in viral infections [142], [143]. Considering that both DNA and RNA viruses and their corresponding PAMPs are NOD2 agonists, modifications of genes associated with NOD2 signalling may be particularly relevant for the innate immune response to SARS-CoV-2, assuming a priori acquisition of trained phenotypes [140]. Furthermore, basal expression levels of NOD2 are higher in macrophages and monocytes in contrast to fibroblast, therefore NOD2 mediated signalling is likely more pronounced in these cells. Of course, this increased potency may translate to increase efficiency with regards to trained immunity.

NOD2 signalling leads to IKB kinase complex (IKK) activation in order to degrade the inhibitory IKBa protein. Synergic IFN-Y and MDP signalling leads to increased IKK activation, thereby significantly reducing IKBa levels in a STAT1 independent fashion [144]. Though understanding of IKK regulation is incomplete, it is known that TNF-a negatively regulates IKK activity by $\mathrm{C}$-terminus phosphorylation of the IKK $\beta$ subunit [28]. Taking this into consideration, it is not difficult to infer that BCG-induced TNF-a may render the BCG vaccine inadequate for therapeutic purposes in COVID-19. A possible way out of this conundrum may lie in the heterogenous BCG-induced cytokine profiles across different populations, which opens the possibility of tailoring different BCG strains in accordance to the populational response [113]. Evidence supporting this suggestion may be extrapolated from the work of Kleinnijenhuis and others, where BCG-induced trained immunity of human monocytes was achieved in a NOD2 and Rip2 dependent manner [115], [145], 


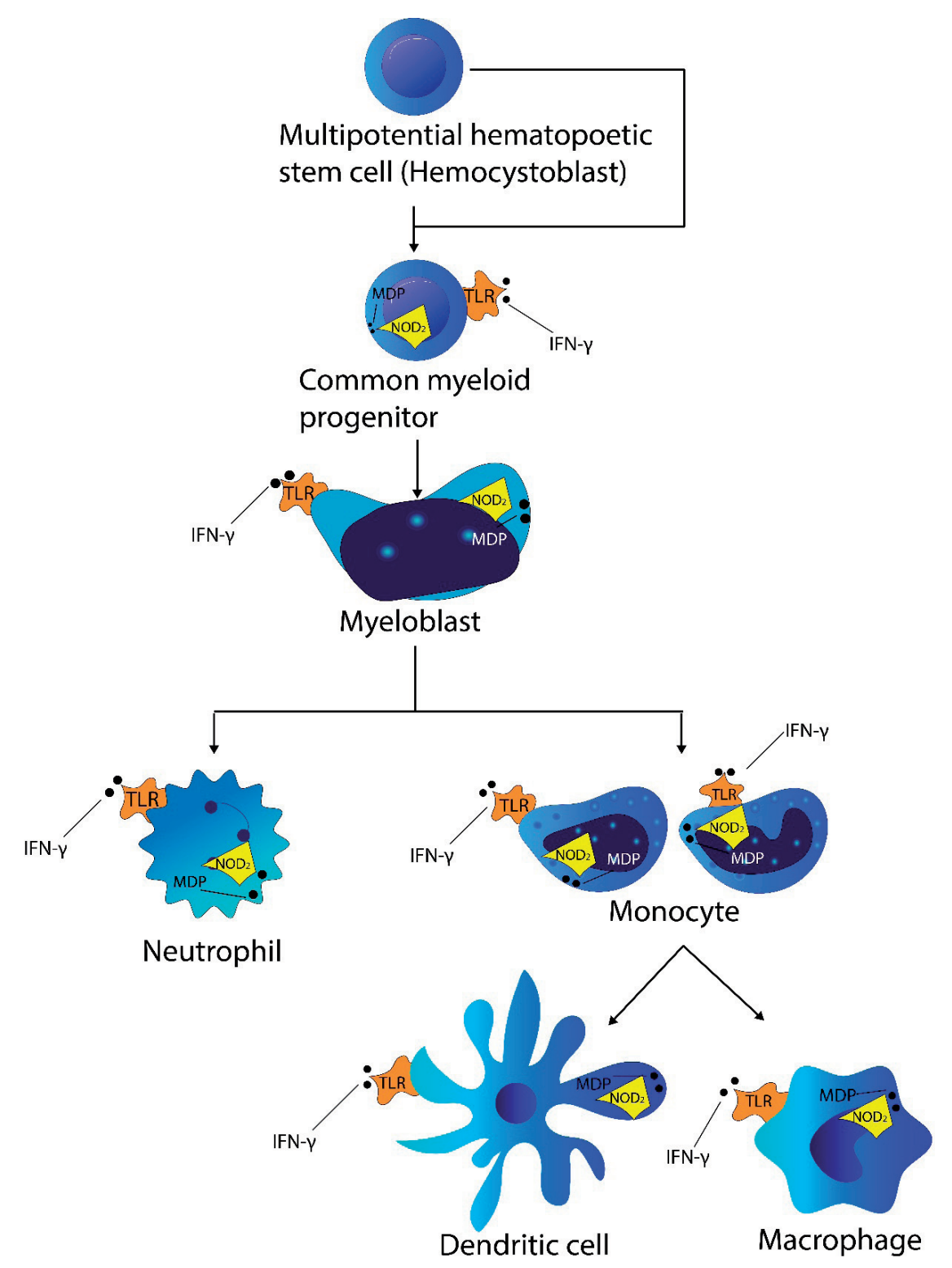

Figure 3. Different cells of the innate immune system can undergo cytokine/antigen-stimulated epigenetic changes that may induced trained immunity. Common myeloid progenitor cells may also be stimulated, thereby differentiating into trained phenotypes. Abbreviations: MDP - muramyl dipeptide, IFN- $y$ - Interferon Gamma, TLR - Toll Like Receptor, NOD2 - Nucleotidebinding oligomerization domain-containing protein 2

[146]. Strikingly, their work demonstrated redundancy of TLR2 and TLR4 in this process, though it is likely that other mechanisms take part in this process that were simply not considered in the work. Considering that SARS-CoV-2 likely blocks ІКB dissociation from NF-KB, it would be interesting to see whether NOD2-dependent trained immunity entails phenotypes that are more resilient to this tactic. Redundancy of TLR2 and TLR4 does not exclude the roll of TLRs in trained immunity, but rather emphasize the complexity and heterogeny of the mechanisms behind it.

\section{A Model of Heterologous Adaptive Immunity for} SARS-CoV-2 Infections

Vaccines were initially considered to eventuate in immune responses precisely tailored towards the pathogen-associated antigen contained within the vaccine. Canonically, once the phagocytic cells engulf an antigen/pathogen, they migrate to proximal lymph nodes and present pathogenassociated peptides (epitopes) to naïve $T$ cells via the type I/II major histocompatibility complex (MHC I/II). In turn, this leads to $T$ and $B$ cell priming, followed by their clonal expansion. The 
traditional interpretation of adaptive immune memory infers that educated lymphocytes are specific only for the epitopes presented by way of MHC molecules. Whilst this specificity, indeed, is predominantly present in the human immune system, a closer inspection of $T$ cell reactivity reveals evidence of heterogenicity, colloquially termed "heterologous immunity". The "off target" vaccine effects that give rise to heterologous immunity lead improved responses to unrelated pathogens and immunological tolerance in autoimmune conditions, though negative effects have also been documented [145], [147]-[151]. Specific mechanisms behind heterologous immunity are poorly understood, however epigenetic programming, cross-reactivity between epitopes and changes in metabolic profiles of lymphocytes, likely play major roles [152]-[155].

\section{Immunological Cross-reactivity of T Cells}

APCs present pathogen-associated epitopes by way of $\mathrm{MHC}$ I and II to $\mathrm{CD} 8^{+}$and $\mathrm{CD} 4^{+} \mathrm{T}$ cells respectively, in the form of short amino acid sequences (MHC I: 8-11, MHC II: 13-17). Hitherto proposed to depend on the presentation of such conserved linear sequences by clonal selection theory, $\mathrm{T}$ cell reactivity evidently extends towards completely unrelated antigenic determinants presented from the MHC antigen-binding groove [152]-[155] (Figure 4). Considering that the amino acid sequences that garner heterologous $T$ cell reactivity are modestly homologous, regular immunological cross-reactivity may be possible not only for unrelated infections, but detrimental in the context of autoimmunity [156], [157]. The root of this heterology is poorly understood, though several plausible mechanisms have been suggested, all of which may, singularly or synergistically, share responsibility for this phenomenon. Though heterologous immunity has thus far been documented in the context of viral infections, BCG vaccination may indirectly lead to heterology through induction of cytokine secretion.

Phenotypic alterations that are to be observed when discussing cross-reactivity, are at the resolution of the T cell receptor (TCR). TCRs are heterodimers comprised of subunits TCRa and TCR $\beta$, though approximately $5 \%$ of human TCRs are comprised of TCRY and TCRס. Expression of TCRs and Ig chains on the surface of T cells is controlled by a mechanism known as allelic

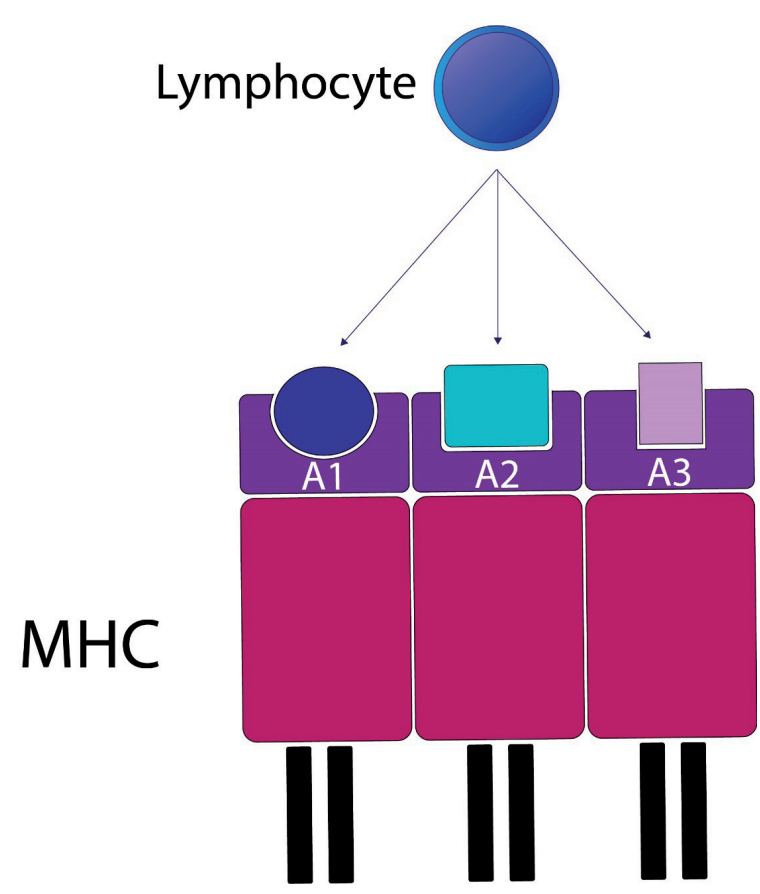

Figure 4. Cross-reactive lymphocytes can respond to different antigen determinants presented on the MHC grooves. Though $T$ cells are most prominently known for cross-reactivity, B cells may also be cross reactive [158]. Abbreviations: MHC - Major Histocompatibility Complex

exclusion, with their expression corresponding to a single allelic copy [16]. This ensures that the modus operandi of $\mathrm{T}$ and $\mathrm{B}$ cell priming is that of clonal selection, the benefit of which entails avoidance of autoimmunity by way of high specificity [13]. However, biallelic expression of TRC and Ig kappa ( $\mathrm{K}$ ) chain (IgK) has been documented in $T$ cells, and correlated with affinity for a broader spectrum of antigens [13], [159]. Of course, this alone cannot be attributed to crossreactivity, as heterogenicity in $T$ and $B$ cell ligand receptor binding is now understood as putative [17]. Interestingly, incomplete allelic exclusion of the TCRa chain can lead to expression of two distinct TCRs, thereby increasing the likelihood of cross-reactivity [18].

Permissive and repressive epigenetic control of $T$ cells, though an integral part of the canonical adaptive response, very likely extend towards the facilitation of heterologous immunity in the context of TCRs and surface Ig [147], [151], [160]-[166]. Though trained immunity is independent from $T$ and $B$ cells, heterologous immunity relies on the canonical relationship between the two components of the immune system. Perhaps characterised with heterogeny, BCG-induced cytokine 
expression profiles predominantly include IFN- $\gamma$, which in turn stimulates macrophages and monocytes to secrete numerous cytokines, including IL-15. This cytokine regulates survival of $T$ cells in the absence of antigens, either through induction of apoptosis or division [167]. It is possible that epigenetic alterations that occur upon BCG vaccination may influence permissiveness of the chromatin regions that corresponds to regulatory regions of the IL-15 gene, though this remains to be determined. In any case, the influence of BCG on heterologous immunity is likely predominantly mediated via innate immune cells. The threshold for TCR activation is lowered in effector/memory $\mathrm{CD}^{+}$cells through the expression of TLR $1 / 2 / 6$ and 6 are respectively. Considering that TLRs are important receptors in BCG recognition, this opens the possibility of epigenetic reprogramming as a result of TLR signalling.

Mycobacterial Activation of Bystander CD $8^{+}$Cells Activation of bystander $\mathrm{CD}^{+}$cells, interestingly enough, is independent of TCRs, yet heavily dependent on secretion of IL-15, which BCG vaccination may indirectly induce [4]. Bystander activation of $\mathrm{CD}^{+}$have been documented as the main sources of IFN- $\gamma$ along with stimulated NK cells in melioidosis caused by Burkholderia pseudomallei [2]. Furthermore, enhanced expression of IFN-y mRNA was documented in mouse models, however the study that reports this used and experimental $M$. avium model [3]. In spite of this, homologies between BCG and $M$. avium antigens may evoke similar, if not identical, $\mathrm{T}$ cell responses. Interestingly, virally activated $\mathrm{CD}^{+}$exhibit strong affinity towards granulomas induced by BCG, though this has thus far only been documented for immunodeficient mice, and it is unclear whether BCG activation of $T$ cells would have the same effect on viral infections [1]. In the absence of more comprehensive studies to draw a conclusion from, it may only be cautiously proposed that BCG-induced IL-15 secretion likely influences bystander $\mathrm{CD} 8^{+} \mathrm{T}$ cell activation.

Though currently available evidence is somewhat suggestive of a relationship between nonspecific $T$ cell activation and BCG immunization, comprehensive work lies ahead in determining whether the vaccine may induce a $\mathrm{CD} 8^{+}$cell phenotype that could contribute to better outcome with SARS-CoV-2. Considering that BCG contains a large number of highly diverse antigens, it is not surprising that $T$ cells induced by BCG vaccination are quite broad in epitope specificity [110], [115], [168]. Per contra, excessive T cell cross-reactivity may lead to autoimmunity, thereby making the heterologous immunity narrative a double-edged sword [13]-[16], [18], [19]. Recently $\mathrm{CD} 4^{+} \mathrm{T}$ cells cross-reactive to SARS-CoV- 2 have been detected in COVID-19 patients, though the exact implications of this remain unclear, and are likely population-specific [169]. However, it has been proposed that their presence could potentially reduce viral loads in both the lungs and the upper respiratory tract upon infection.

\section{Non-specific Immunomodulatory Effects of the BCG Vaccine}

Reports of non-specific benefits of BCG vaccination on other infectious diseases has seen a steady increase in recent years, correlating the vaccine with reduced mortality rate among infants, along with adjuvant-like effects on other unrelated childhood vaccines [170]. Beneficial effects of BCG on non-mycobacterial infections is colloquially thought to be mediated by innate immune memory or heterologous lymphocyte activation [30], [171], due the absence pathogen-specific antibody epitopes in mouse studies where the vaccine conferred a better outcome in infections with Salmonella typhimurium and challenges with Plasmodium spp. and Babesia [172]. Perhaps the most striking evidence regarding non-specific BCG benefit is the improved antibody response to oral polio vaccine boosting detected in patients who were also given BCG at the time of booster administration [173], [174]. Thus, it is likely that the beneficial effects of the BCG vaccine vary concordantly to the strain of BCG and the immunogenetic background of the host. For instance, an Australian study conducted on 56 BCG-vaccinated and 52 BCG nonvaccinated infants, uncovered higher titters of IgG with epitopes for Haemophilus influenzae type B polysaccharides, pneumococcal capsular polysaccharide PAMPs and tetanus toxoid (TT) [175]. Per contra, a randomized study on new-borns in Denmark found that a reduction in infant hospitalizations was only for cases where the mothers were also BCG vaccinated [176], [177].

Non-specific BCG effects do not shy away from the domain of respiratory viral infections, 
where beneficial effects of BCG continue to be reported, however comprehensive understanding of this puzzling occurrence is modest at best [8], [31], [120]. Although a number of different BCG strains exist and continue to be regularly used, there is very limited work on the efficacy conferred by each different strain, both in tuberculosis prophylaxis and non-specific effects in non-

Table 1. Some currently ongoing clinical trials regarding the correlation of the BCG vaccine and reduced risk of COVID-19 (https:// clinicaltrials.gov/)

\begin{tabular}{|c|c|c|c|}
\hline Title & Status & Interventions & Locations \\
\hline $\begin{array}{l}\text { Reducing Health Care } \\
\text { Workers Absenteeism } \\
\text { in Covid-19 Pandemic } \\
\text { Through BCG Vaccine }\end{array}$ & $\begin{array}{l}\text { Active, not } \\
\text { recruiting }\end{array}$ & $\begin{array}{l}\text { - Drug: BCG Vaccine } \\
\text { - Drug: Placebo }\end{array}$ & $\begin{array}{l}\text { - Jeroen Bosch ziekenhuis, Den Bosch, Brabant, } \\
\text { Netherlands } \\
\text { - Canisius Wilhelmina Ziekenhuis, Nijmegen, Gelderland, } \\
\text { Netherlands } \\
\text { - Radboud UMC, Nijmegen, Gelderland, Netherlands } \\
\text { - Sint Maartenskliniek, Nijmegen, Gelderland, } \\
\text { Netherlands } \\
\text { - Noordwest Ziekenhuisgroep locatie Alkmaar, Alkmaar, } \\
\text { Noord Holland, Netherlands } \\
\text { - Hagaziekenhuis, Den Haag, Zuid-Holland, Netherlands } \\
\text { - Leiden University Medical Center, Leiden, Zuid-Holland, } \\
\text { Netherlands } \\
\text { - Erasmus Medical Center, Rotterdam, Zuid-Holland, } \\
\text { Netherlands } \\
\text { - University Medical Center Utrecht, Utrecht, Netherlands }\end{array}$ \\
\hline $\begin{array}{l}\text { Reducing COVID-19 } \\
\text { Related Hospital } \\
\text { Admission in Elderly by } \\
\text { BCG Vaccination }\end{array}$ & $\begin{array}{l}\text { Active, not } \\
\text { recruiting }\end{array}$ & $\begin{array}{l}\text { - Biological: BCG vaccine } \\
\text { - Biological: Placebo }\end{array}$ & $\begin{array}{l}\text { - Radboud University, Nijmegen, Gelderland, Netherlands } \\
\text { - UMC Utrecht, Utrecht, Netherlands }\end{array}$ \\
\hline $\begin{array}{l}\text { BCG Vaccination for } \\
\text { Healthcare Workers in } \\
\text { COVID-19 Pandemic }\end{array}$ & $\begin{array}{l}\text { Active, not } \\
\text { recruiting }\end{array}$ & $\begin{array}{l}\text { - Biological: Bacille Calmette- } \\
\text { Guérin (BCG) } \\
\text { - Other: Placebo Comparator }\end{array}$ & $\begin{array}{l}\text { - TASK Foundation, Cape Town, Western Cape, South } \\
\text { Africa }\end{array}$ \\
\hline $\begin{array}{l}\text { BCG Vaccination to } \\
\text { Protect Healthcare } \\
\text { Workers Against } \\
\text { COVID-19 }\end{array}$ & $\begin{array}{l}\text { Active, not } \\
\text { recruiting }\end{array}$ & $\begin{array}{l}\text { - Drug: } \mathrm{BCG} \text { Vaccine } \\
\text { - Drug: } 0.9 \% \mathrm{NaCl}\end{array}$ & $\begin{array}{l}\text { - St Vincent's Hospital, Sydney, Sydney, New South } \\
\text { Wales, Australia } \\
\text { - Prince of Wales Hospital, Sydney, New South Wales, } \\
\text { Australia } \\
\text { - Sydney Children's Hospital, Randwick, Sydney, New } \\
\text { South Wales, Australia } \\
\text { - The Children's Hospital at Westmead, Sydney, New } \\
\text { South Wales, Australia } \\
\text { - Westmead Hospital, Sydney, New South Wales, Australia } \\
\text { - Royal Adelaide Hospital, Adelaide, South Australia, } \\
\text { Australia } \\
\text { - Women's and Children's Hospital, North Adelaide, South } \\
\text { Australia, Australia } \\
\text { - Royal Children's Hospital, Melbourne, Victoria, Australia } \\
\text { - Epworth Richmond, Melbourne, Victoria, Australia } \\
\text { - Monash Health- Monash Medical Centre, Melbourne, } \\
\text { Victoria, Australia } \\
\text { - and } 26 \text { more }\end{array}$ \\
\hline $\begin{array}{l}\text { Prevention, Efficacy } \\
\text { and Safety of BCG } \\
\text { Vaccine in COVID-19 } \\
\text { Among Healthcare } \\
\text { Workers }\end{array}$ & $\begin{array}{l}\text { Active, not } \\
\text { recruiting }\end{array}$ & $\begin{array}{l}\text { - Biological: BCG vaccine } \\
\text { - Other: Placebo }\end{array}$ & $\begin{array}{l}\text { - Hospital Universitario "José E. González", Monterrey, } \\
\text { Nuevo León, Mexico }\end{array}$ \\
\hline $\begin{array}{l}\text { BCG Vaccine in } \\
\text { Reducing Morbidity } \\
\text { and Mortality in Elderly } \\
\text { Individuals in COVID- } \\
19 \text { Hotspots }\end{array}$ & $\begin{array}{l}\text { Active, not } \\
\text { recruiting }\end{array}$ & $\begin{array}{l}\text { - Biological: BCG vaccine } \\
\text { (Freeze-dried) }\end{array}$ & $\begin{array}{l}\text { - Tuberculosis Research Centre, Chennai, Tamilnadu, } \\
\text { India }\end{array}$ \\
\hline $\begin{array}{l}\text { Efficacy and Safety of } \\
\text { VPM1002 in Reducing } \\
\text { SARS-CoV-2 (COVID- } \\
\text { 19) Infection Rate and } \\
\text { Severity }\end{array}$ & $\begin{array}{l}\text { Active, not } \\
\text { recruiting }\end{array}$ & $\begin{array}{l}\text { - Biological: VPM1002 } \\
\text { - Other: Placebo }\end{array}$ & - University Health Network, Toronto, Ontario, Canada \\
\hline
\end{tabular}


mycobacterial infectious diseases. There is some evidence indicating that BCG decreases the morbidity of acute lower respiratory tract infections caused by respiratory syncytial virus (RSV); this effect was observed in young children in Guinea-Bissau and in a study that included elderly people, where a decrease in incidence of acute upper respiratory tract infections was reported [178]. However, it should be noted that the study on elderly people, which did yield positive results in favour of the non-specific protection of BCG against viral infections, was conducted by administering the vaccine once a month for three months, thereby warranting cautious interpretation. A significant reduction in respiratory tract infections was also reported in a study of BCGvaccinated adolescents in the South-African population [179]-[181]. Although the results of these studies are in favour of non-specific prophylactic BCG effects in viral infections, therapeutic effects of the vaccine have also been reported, specifically regarding patients infected with the human papilloma virus (HPV) [182].

Perhaps most interesting for the COVID19 pandemic is a study that reported improved antibody titters for the influenza A strain (H1N1) that caused the 2009 "swine flu" epidemic, when BCG was administered prior to the H1N1 vaccine. The enhanced protection was hallmarked by an improved production of IFN- $\gamma$ for the H1N1 study [183], contrasted with another study that reported that BCG-induced IL-1 $\beta$ production is the likely mechanism of conferred protection during viral infections [151]. However, the same IFN- $y$ - mediated protection was observed for the vaccinia virus in infected mice upon BCG vaccination, which promoted the secretion of this cytokine by $C D 4^{+} T$ cells [184]-[186]. IL-1 $\beta$ plays a role in inflammatory responses, apoptosis, cell differentiation and proliferation, and has shown to play an important role in viral immunity [187]. Improvement of non-specific Th1 and Th17 immune responses, along with enhanced innate trained immunity, has also been reported in BCG-immunized patients, with satisfactory durations [188].

\section{Implications for the COVID-19 Pandemic}

At the present moment, there are a number of clinical trials aimed at evaluating the presumed protective effects of the BCG vaccine towards COVID-19, some of which are summarized in Table 1. It is likely, however, that BCG strain will have an impact on its effects on COVID-19 and infections with SARS-CoV-2, and trials are currently underway for the purpose of assessing which strain, if any, is adequate for implementation in the battle against COVID-19. Thus far, the candidates of interest are the Danish and Tokyo strain, although it currently remains utterly unclear what the immunological basis for their difference in efficacy might be [106]. Frequently used BCG strained along with their characteristics are summarized in Table 2 [189], [190]. Virulence of the BCG strain was hypothesized to play a role in protection against Mycobacterium tuberculosis, potentiating the assumption that the trials will eventuate in varying efficacy across BCG strains for COVID-19 [43]. There is an obvi-

Table 2. Summarization of frequently used BCG vaccines and their characteristics. Abbreviations: CRR, complete response rate; $\mathrm{NA}$, not applicable

\begin{tabular}{lccccc} 
Strain & Mean CRR & $\begin{array}{c}\text { Weight } \\
(\mathrm{mg})\end{array}$ & $\begin{array}{c}\text { Recommended } \\
\text { dose }(\mathrm{cfu})^{ \pm}\end{array}$ & $\begin{array}{c}\text { Secretion of lipid } \\
\text { virulence factors }\end{array}$ & $\begin{array}{c}\text { Secretion of MPB64/ } \\
\text { MPB70 and MPB8 }\end{array}$ \\
\hline RIVM/1 & 60 & 80 & $2-30 \times 10^{8}$ & NT & Unknown \\
\hline Romanian & 64 & NA & NA & NT & Unknown \\
\hline Copenhagen & 67 & NA & NA & Yes & Absent/Present \\
\hline S. African & 69 & NA & NA & NT & Unknown \\
\hline A. Frappier & $60(39-100)$ & NA & NA & Yes & Absent/Present \\
\hline Glaxo & $65(53-88)$ & NA & NA & No & Absent/Present \\
\hline Tice & $71(56-82)$ & 12.5 & $2-8 \times 10^{8}$ & Yes & Absent/Present \\
\hline Pasteur & $74(40-80)$ & NA & NA & Yes & Absent/Present \\
\hline Tokyo & $77(63-84)$ & 80 & $0.4-0.5 \times 10^{8}$ & No & Present/High \\
\hline Connaught & $79(70-92)$ & 81 & $1.8-15.9 \times 10^{8}$ & NT & Unknown \\
\hline Moreau RdJ & 90 & 80 & $0.04 \times 10^{8}$ & No & Present/High \\
\hline Moscow & 90.5 & 120 & $3-57 \times 10^{8}$ & Yes & Present/High
\end{tabular}



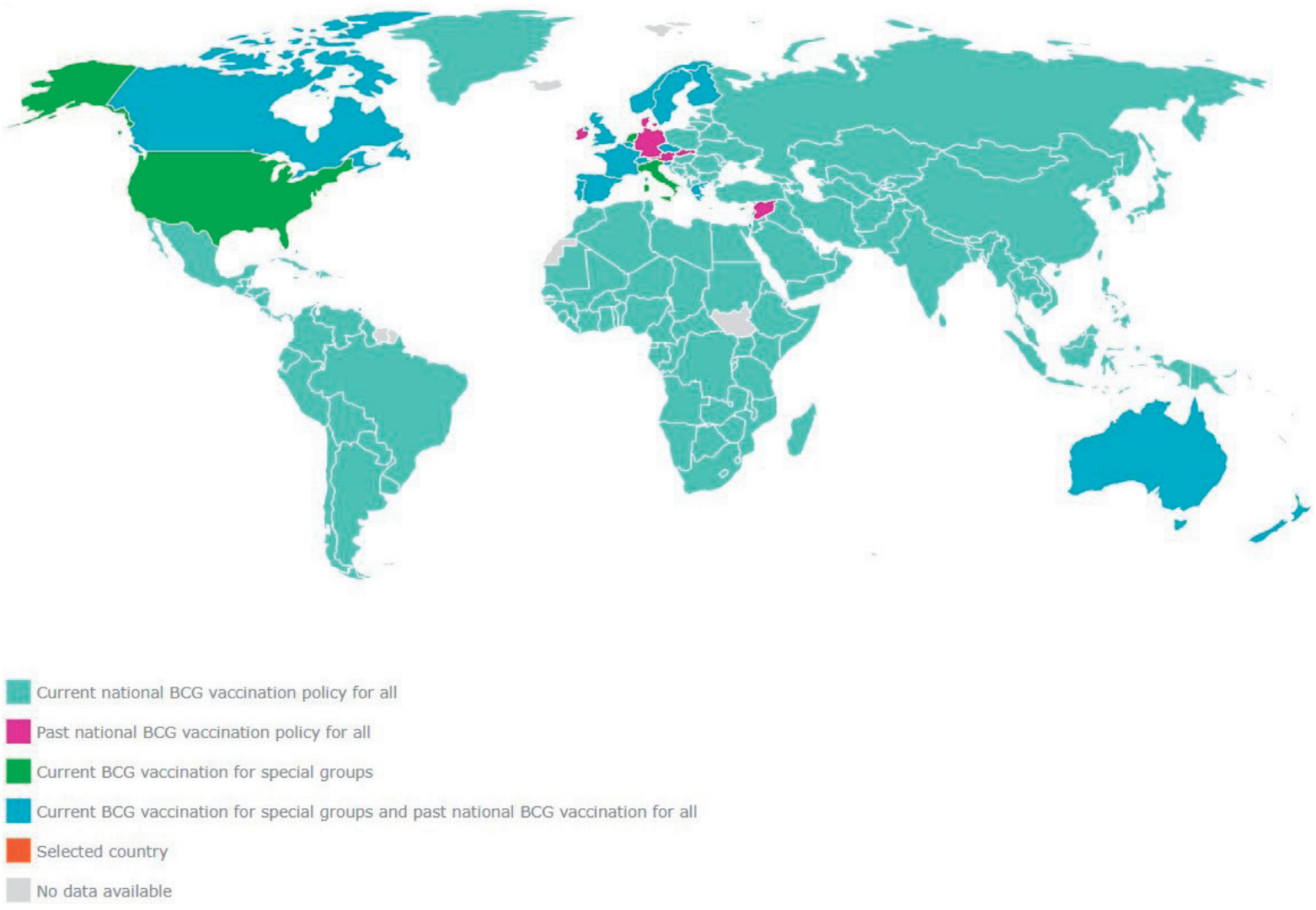

ous need to bridge the gap between findings in basic immunobiology and clinical application, which will hopefully occur upon the conclusion of these clinical trials. Since COVID-19 vaccines are still not internationally widely available to all countries, the potential for utilization of existing vaccine technologies in mitigating some of the fallout caused by COVID-19, could significantly improve patient care in countries where COVID19 vaccines are scarcely available.

\section{Concluding Remarks}

Although the mechanisms of action remain unclear, non-specific effects of BCG have been reported to confer a degree of protection against viral infections and non-mycobacterial bacterial infections. It is likely that BCG predominantly influences innate immune memory, causing epigenetic modulation of monocytes and macrophages, and inducing secretion immunomodulating cytokines. Effects on heterologous immunity, however, can currently only be described as indirect, particularly through induction of IL-15 secretion. Though heterologous immunity does, indeed, depend on adequate pathogen process- ing by the innate immune system, BCG-induced bystander $\mathrm{CD} 8^{+}$activation may boost the innate immune response through enhanced IFN-y production.

Although recent studies have shown that BCG promotes the Th1 and Th17 immune response, further studies should be directed at uncovering whether such effects are dependent on BCG strain and the immunogenetic background of patients. Considering that BCG has been shown to increase titters of polysaccharide-specific IgG in bacterial infections, it is possible that the same might be true in the case of SARS-CoV-2 spike glycoprotein, which the virus uses to bind to cells expressing ACE2 and C-type lectins. Substantial evidence has mounted over the years in favour of non-specific benefits of BCG vaccination in a variety of other infectious and oncologic diseases, further solidifying the plausibility of this model. However, the effects of this vaccine vary in accordance to BCG strain and likely a plethora of host-derived factors, most of which are incompletely understood. In essence, trained and heterologous immunity are incredibly complex and multifaceted phenomena with proven therapeutic potential, and could possibly confer improved outcome in asymptomatic SARS-CoV-2 infec- 
tions, or COVID19 disease. It is encouraging to see the number of clinical trials that are currently underway, tasked with resolving a lot of unclarity regarding the issue of BCG-induced heterologous immunity. Though this work is concerned with providing a hypothetical model by which the BCG vaccine may induce non-specific protection against SARS-Cov-2 - based on studies concerning other pathogens - we recognize the limitations of all previous studies pertaining to this topic. Firstly, though this is a plausible immunobiological model, it largely based on in vitro and animal studies, with several prominent examples derived from human test subjects. Human studies concerning heterologous immunity tend to suffer from the issue of bias, and the potentially relevant host-derived intricacies influencing the ability of a vaccine to influence innate immune cell memory, is difficult to control for. Though our model holds plausibility, it should be understood as suggestive rather than definitive, and more work is definitely needed - one that bridges clinical relevance and basic immunobiological studies - in order to derive a definitive conclusion.

\section{Acknowledgements}

Special thanks go to prof. Andrej A. Gajić from National Geographic, for his continuous support and mentoring throughout this and other works of the author related to tuberculosis and other infectious diseases; prof. Monia Avdić, Ph.D., from International Burch University, for her mentoring in the subject of immunology and microbiology, and to all friends and colleagues who have supported this work with their unbiased critique.

\section{Conflict of interest statement}

The authors declare no conflict of interest.

\section{Ethical approval and consent to participate}

Not applicable.

\section{Funding sources}

There are no sources of funding to declare.

\section{Availability of supporting data}

This is a review; therefore, this is not applicable. Each of the studies that this manuscript is based on are publicly available.

\section{References}

1. LH. Hogan, DO. Co, J. Karman, E. Heninger, M. Suresh, and M. Sandor, "Virally activated CD8 T cells home to Mycobacterium bovis BCG-induced granulomas but enhance antimycobacterial protection only in immunodeficient mice," Infection and Immunity, vol. 75, no. 3, pp. 1154-1166, Mar. 2007, doi: 10.1128/IAI.00943-06.
2. G. Lertmemongkolchai, G. Cai, CA. Hunter, and GJ. Bancroft, "Bystander Activation of CD8 + T Cells Contributes to the Rapid Production of IFN-y in Response to Bacterial Pathogens," The Journal of Immunology, vol. 166, no. 2, pp. 1097-1105, Jan. 2001, doi: 10.4049/jimmunol.166.2.1097.

3. B. Gilbertson, S. Germano, P. Steele, S. Turner, BF. Barbara, and C. Cheers, "Bystander activation of CD8+ $T$ lymphocytes during experimental mycobacterial infection," Infection and Immunity, vol. 72 , no. 12 , pp. $6884-6891$, Dec. 2004 , doi: 10.1128 / IAI.72.12.6884-6891.2004.

4. J. Kim et al., "Innate-like Cytotoxic Function of Bystander-Activated CD8 $+\mathrm{T}$ Cells Is Associated with Liver Injury in Acute Hepatitis A," Immunity, vol. 48, no. 1, pp. 161-173.e5, Jan. 2018, doi: 10.1016/j. immuni.2017.11.025.

5. DJ. Perkins, MC. Patel, JCG. Blanco, and SN. Vogel, "Epigenetic mechanisms governing innate inflammatory responses," Journal of Interferon and Cytokine Research, vol. 36, no. 7, pp. 454-461, Jul. 2016, doi: 10.1089/jir.2016.0003.

6. B. Gourbal, S. Pinaud, GJM. Beckers, JWM. van der Meer, U. Conrath, and MG. Netea, "Innate immune memory: An evolutionary perspective," Immunological Reviews, vol. 283, no. 1, pp. $21-40$, May 2018, doi: 10.1111/imr.12647.

7. E. Töpfer, D. Boraschi, and P. Italiani, "Innate Immune Memory: The Latest Frontier of Adjuvanticity," Journal of Immunology Research, vol. 2015, 2015, doi: $10.1155 / 2015 / 478408$.

8. MG. Netea and R. van Crevel, "BCG-induced protection: Effects on innate immune memory," Seminars in Immunology, vol. 26, no. 6, pp. 512-517, Dec. 2014, doi: 10.1016/j.smim.2014.09.006.

9. JD. van Belleghem and PL. Bollyky, "Macrophages and innate immune memory against Staphylococcus skin infections," Proceedings of the National Academy of Sciences of the United States of America, vol. 115 , no. 47, pp. 11865-11867, Nov. 2018, doi: 10.1073/ pnas. 1816935115.

10. D. Boraschi and P. Italiani, "Innate immune memory: Time for adopting a correct terminology," Frontiers in Immunology, vol. 9, no. APR, p. 799, Apr. 2018, doi: 10.3389/fimmu.2018.00799.

11. VA.CM. Koeken, AJ. Verrall, MG. Netea, PC. Hill, and R. van Crevel, "Trained innate immunity and resistance to Mycobacterium tuberculosis infection," Clinical Microbiology and Infection, vol. 25, no. 12. Elsevier BV., pp. 1468-1472, Dec. 01, 2019. doi: 10.1016/j. cmi.2019.02.015.

12. B. Pulendran and R. Ahmed, "Translating innate immunity into immunological memory: Implications for vaccine development," Cell, vol. 124, no. 4, pp. 849-863, Feb. 2006, doi: 10.1016/j.cell.2006.02.019.

13. BL. Brady, NC. Steinel, and CH. Bassing, "Antigen Receptor Allelic Exclusion: An Update and Reappraisal," The Journal of Immunology, vol. 185, no. 7, pp. 3801-3808, Oct. 2010, doi: 10.4049/jimmunol.1001158.

14. R. Levin-Klein and Y. Bergman, "Epigenetic regulation of monoallelic rearrangement (allelic exclusion) 
of antigen receptor genes," Frontiers in Immunology, vol. 5, no. DEC, p. 625, Dec. 2014, doi: 10.3389/ fimmu.2014.00625.

15. Y. Bergman and H. Cedar, "A stepwise epigenetic process controls immunoglobulin allelic exclusion," Nature Reviews Immunology, vol. 4, no. 10, pp. 753761, Oct. 2004, doi: 10.1038/nri1458.

16. P. Borst, "Antigenic variation and allelic exclusion," Cell, vol. 109, no. 1, pp. 5-8, Apr. 2002, doi: 10.1016/ S0092-8674(02)00711-0.

17. KW. Wucherpfennig et al., "Polyspecificity of $\mathrm{T}$ cell and B cell receptor recognition," Seminars in Immunology, vol. 19, no. 4, pp. 216-224, Aug. 2007, doi: 10.1016/j.smim.2007.02.012.

18. M. Malissen, J. Trucy, E. Jouvin-Marche, PA. Cazenave, R. Scollay, and B. Malissen, "Regulation of TCR $a$ and $\beta$ gene allelic exclusion during T-cell development," Immunology Today, vol. 13, no. 8, pp. 315-322, 1992, doi: 10.1016/0167-5699(92)90044-8.

19. AK. Sewell, "Why must T cells be cross-reactive?," Nature Reviews Immunology, vol. 12, no. 9, pp. 669677, Sep. 2012, doi: 10.1038/nri3279.

20. I. Santecchia et al., "Innate immune memory through TLR2 and NOD2 contributes to the control of Leptospira interrogans infection," PLOS Pathogens, vol. 15, no. 5, p. e1007811, May 2019, doi: 10.1371/journal. ppat.1007811.

21. C. Yan and DD. Boyd, "Histone $\mathrm{H} 3$ Acetylation and $\mathrm{H} 3$ K4 Methylation Define Distinct Chromatin Regions Permissive for Transgene Expression," Molecular and Cellular Biology, vol. 26, no. 17, pp. 6357-6371, Sep. 2006, doi: 10.1128/mcb.00311-06.

22. VR. Ramirez-Carrozzi et al., "Selective and antagonistic functions of SWI/SNF and Mi-2 $\beta$ nucleosome remodeling complexes during an inflammatory response," Genes and Development, vol. 20, no. 3, pp. 282-296, Feb. 2006, doi: 10.1101/gad.1383206.

23. VR. Ramirez-Carrozzi et al., "A Unifying Model for the Selective Regulation of Inducible Transcription by $\mathrm{CpG}$ Islands and Nucleosome Remodeling," Cell, vol. 138, no. 1, pp. 114-128, Jul. 2009, doi: 10.1016/j. cell.2009.04.020.

24. DC. Hargreaves, T. Horng, and R. Medzhitov, "Control of Inducible Gene Expression by Signal-Dependent Transcriptional Elongation," Cell, vol. 138, no. 1, pp. 129-145, Jul. 2009, doi: 10.1016/j.cell.2009.05.047.

25. EL. Lousberg, CK. Fraser, MG. Tovey, KR. Diener, and JD. Hayball, "Type I Interferons Mediate the Innate Cytokine Response to Recombinant Fowlpox Virus but Not the Induction of Plasmacytoid Dendritic CellDependent Adaptive Immunity," Journal of Virology, vol. 84 , no. 13 , pp. 6549-6563, Jul. 2010, doi: 10.1128/ jvi.02618-09.

26. R. Kamada et al., "Interferon stimulation creates chromatin marks and establishes transcriptional memory," Proceedings of the National Academy of Sciences of the United States of America, vol. 115, no. 39, pp. E9162-E9171, Sep. 2018, doi: 10.1073/ pnas.1720930115.

27. CM. Leopold Wager et al., "IFN- $\gamma$ immune priming of macrophages in vivo induces prolonged STAT1 binding and protection against Cryptococcus neoform- ans," PLoS Pathogens, vol. 14, no. 10, Oct. 2018, doi: 10.1371/journal.ppat.1007358.

28. MK. Lalor et al., "BCG vaccination induces different cytokine profiles following infant BCG vaccination in the UK and Malawi," Journal of Infectious Diseases, vol. 204, no. 7, pp. 1075-1085, Oct. 2011, doi: 10.1093/infdis/jir515.

29. SJ.CFM. Moorlag, RJW. Arts, R. van Crevel, and MG. Netea, "Non-specific effects of BCG vaccine on viral infections," Clinical Microbiology and Infection, vol. 25, no. 12. Elsevier BV., pp. 1473-1478, Dec. 01, 2019. doi: 10.1016/j.cmi.2019.04.020.

30. IA. Clark, AC. Allison, and FE. Cox, "Protection of mice against Babesia, and Plasmodium with BCG," Nature, vol. 259 , no. 5541 , pp. 309-311, 1976, doi: 10.1038/259309a0.

31. LAJ. O'Neill and MG. Netea, "BCG-induced trained immunity: can it offer protection against COVID-19?," Nature Reviews Immunology, vol. 20, no. 6. Nature Research, pp. 335-337, Jun. 01, 2020. doi: 10.1038/ s41577-020-0337-y.

32. SM. Taghioff, BR. Slavin, T. Holton, and D. Singh, "Examining the potential benefits of the influenza vaccine against SARS-CoV-2: A retrospective cohort analysis of 74,754 patients," PLOS ONE, vol. 16, no. 8, p. e0255541, Aug. 2021, doi: 10.1371/JOURNAL. PONE.0255541.

33. A. Conlon, C. Ashur, L. Washer, KA. Eagle, and MA. Hofmann Bowman, "Impact of the influenza vaccine on COVID-19 infection rates and severity," American Journal of Infection Control, vol. 49, no. 6, pp. 694700, Jun. 2021, doi: 10.1016/J.AJIC.2021.02.012.

34. K. Huang, SW. Lin, WH. Sheng, and CC. Wang, "Influenza vaccination and the risk of COVID-19 infection and severe illness in older adults in the United States," Scientific Reports 2021 11:1, vol. 11, no. 1, pp. 1-6, May 2021, doi: 10.1038/s41598-021-90068-y.

35. FK. Föhse et al., "The BNT162b2 mRNA vaccine against SARS-CoV-2 reprograms both adaptive and innate immune responses," medRxiv, p. 2021.05.03.21256520, May 2021, doi: 10.1101/2021.05.03.21256520.

36. A. Miller, MJ. Reandelar, K. Fasciglione, V. Roumenova, Y. Li, and GH. Otazu, "Correlation between universal BCG vaccination policy and reduced morbidity and mortality for COVID-19: an epidemiological study", doi: 10.1101/2020.03.24.20042937.

37. S. Perlman and AA. Dandekar, "Immunopathogenesis of coronavirus infections: Implications for SARS," Nature Reviews Immunology, vol. 5, no. 12. pp. 917927, Dec. 01, 2005. doi: 10.1038/nri1732.

38. I. Glowacka, S. Bertram, and S. PöhImann, "Cellular Entry of the SARS Coronavirus: Implications for Transmission, Pathogenicity and Antiviral Strategies," Molecular Biology of the Sars-coronavirus, pp. 3-22, Jul. 2009, doi: 10.1007/978-3-642-03683-5_1.

39. J. He, H. Tao, Y. Yan, S.-Y. Huang, and Y. Xiao, "Molecular Mechanism of Evolution and Human Infection with SARS-CoV-2," Viruses, vol. 12, no. 4, p. 428, Apr. 2020, doi: 10.3390/v12040428.

40. VK. Shah, P. Firmal, A. Alam, D. Ganguly, and S. Chattopadhyay, "Overview of Immune Response Dur- 
ing SARS-CoV-2 Infection: Lessons From the Past," Frontiers in Immunology, vol. 11, p. 1949, Aug. 2020, doi: 10.3389/fimmu.2020.01949.

41. M. Letko, A. Marzi, and V. Munster, "Functional assessment of cell entry and receptor usage for SARS-CoV-2 and other lineage B betacoronaviruses," Nature Microbiology, vol. 5, no. 4, pp. 562-569, 2020, doi: 10.1038/s41564-020-0688-y.

42. R. Lu et al., "Genomic characterisation and epidemiology of 2019 novel coronavirus: implications for virus origins and receptor binding," www.thelancet.com, vol. 395 , p. 565, 2020, doi: 10.1016/S01406736(20)30251-8.

43. L. Lin, L. Lu, W. Cao, and T. Li, "Hypothesis for potential pathogenesis of SARS-CoV-2 infection-a review of immune changes in patients with viral pneumonia," Emerging Microbes \& Infections, vol. 9, no. 1, pp. 727732, Jan. 2020, doi: 10.1080/22221751.2020.1746199.

44. N. Zhu et al., "A novel coronavirus from patients with pneumonia in China, 2019," New England Journal of Medicine, vol. 382, no. 8, pp. 727-733, Feb. 2020, doi: 10.1056/NEJMoa2001017.

45. D. Harmer, M. Gilbert, R. Borman, and KL. Clark, "Quantitative mRNA expression proçling of ACE 2 , a novel homologue of angiotensin converting enzyme."

46. F. Ali, A. Kasry, and M. Amin, "The new SARS-CoV-2 strain shows a stronger binding affinity to ACE2 due to N501Y mutant," Medicine in Drug Discovery, vol. 10, p. 100086, Jun. 2021, doi: 10.1016/J. MEDIDD.2021.100086.

47. J. Shang et al., "Structural basis of receptor recognition by SARS-CoV-2," Nature, vol. 581, no. 7807, pp. 221-224, May 2020, doi: 10.1038/s41586-0202179-y.

48. M. Murakami, D. Kamimura, and T. Hirano, "Pleiotropy and Specificity: Insights from the Interleukin 6 Family of Cytokines," Immunity, vol. 50, no. 4, pp. 812831, Apr. 2019, doi: 10.1016/j.immuni.2019.03.027.

49. F. Chiodo et al., "Novel ACE2-Independent Carbohydrate-Binding of SARS-CoV-2 Spike Protein to Host Lectins and Lung Microbiota," bioRxiv, p. 2020.05.13.092478, May 2020, doi: 10.1101/2020.05.13.092478

50. SA. Jeffers et al., "CD209L (L-SIGN) is a receptor for severe acute respiratory syndrome coronavirus," Proceedings of the National Academy of Sciences of the United States of America, vol. 101, no. 44, pp. 1574815753, Nov. 2004, doi: 10.1073/pnas.0403812101.

51. R. Amraie et al., "CD209L/L-SIGN and CD209/DCSIGN act as receptors for SARS-CoV-2 and are differentially expressed in lung and kidney epithelial and endothelial cells," bioRxiv: the preprint server for biology, 2020, doi: 10.1101/2020.06.22.165803.

52. E. Prompetchara, C. Ketloy, and T. Palaga, "Immune responses in COVID-19 and potential vaccines: Lessons learned from SARS and MERS epidemic," Asian Pacific Journal of Allergy and Immunology, 2020, doi: 10.12932/AP-200220-0772.

53. E. de Wit, N. van Doremalen, D. Falzarano, and VJ. Munster, "SARS and MERS: Recent insights into emerging coronaviruses," Nature Reviews Microbiol- ogy, vol. 14, no. 8. Nature Publishing Group, pp. 523534, Aug. 01, 2016. doi: 10.1038/nrmicro.2016.81.

54. T. Yoshikawa, T. Hill, K. Li, CJ. Peters, and C.-TK. Tseng, "Severe Acute Respiratory Syndrome (SARS) Coronavirus-Induced Lung Epithelial Cytokines Exacerbate SARS Pathogenesis by Modulating Intrinsic Functions of Monocyte-Derived Macrophages and Dendritic Cells," Journal of Virology, vol. 83, no. 7, pp. 3039-3048, Apr. 2009, doi: 10.1128/jvi.01792-08.

55. J. Zhao, J. Zhao, K. Legge, and S. Perlman, "Age-related increases in PGD 2 expression impair respiratory $\mathrm{DC}$ migration, resulting in diminished $\mathrm{T}$ cell responses upon respiratory virus infection in mice," Journal of Clinical Investigation, vol. 121, no. 12, pp. 4921-4930, Dec. 2011, doi: 10.1172/JCI59777.

56. JS. Turner et al., "SARS-CoV-2 infection induces long-lived bone marrow plasma cells in humans," Nature 2021 595:7867, vol. 595, no. 7867, pp. 421425, May 2021, doi: 10.1038/s41586-021-03647-4.

57. Z. Wang et al., "Naturally enhanced neutralizing breadth against SARS-CoV-2 one year after infection," Nature 2021 595:7867, vol. 595, no. 7867, pp. 426-431, Jun. 2021, doi: 10.1038/s41586-02103696-9.

58. A. Sette and S. Crotty, "Adaptive immunity to SARSCoV-2 and COVID-19," Cell, vol. 184, no. 4, p. 861, Feb. 2021, doi: 10.1016/J.CELL.2021.01.007.

59. K. -Y Yuen et al., "Coronavirus Disease 2019 (COVID19) Re-infection by a Phylogenetically Distinct Severe Acute Respiratory Syndrome Coronavirus 2 Strain Confirmed by Whole Genome Sequencing," Clinical Infectious Diseases, vol. 73, no. 9, pp. e2946-e2951, Nov. 2021, doi: 10.1093/CID/CIAA1275.

60. RL. Tillett et al., "Genomic evidence for reinfection with SARS-CoV-2: a case study," The Lancet Infectious Diseases, vol. 21, no. 1, pp. 52-58, Jan. 2021, doi: 10.1016/S1473-3099(20)30764-7.

61. R. Medzhitov and CA. Janeway, "Innate immunity: Impact on the adaptive immune response," Current Opinion in Immunology, vol. 9, no. 1, pp. 4-9, Feb. 1997, doi: 10.1016/S0952-7915(97)80152-5.

62. L. Mohamed Khosroshahi, M. Rokni, T. Mokhtari, and F. Noorbakhsh, "Immunology, immunopathogenesis and immunotherapeutics of COVID-19; an overview," International Immunopharmacology, vol. 93, p. 107364, Apr. 2021, doi: 10.1016/J. INTIMP.2020.107364.

63. WJ. Liu et al., "T-cell immunity of SARS-CoV: Implications for vaccine development against MERS-CoV," Antiviral Research, vol. 137. Elsevier BV., pp. 82-92, Jan. 01, 2017. doi: 10.1016/j.antiviral.2016.11.006.

64. L. Cheng et al., "Dynamic landscape mapping of humoral immunity to SARS-CoV-2 identifies nonstructural protein antibodies associated with the survival of critical COVID-19 patients," Signal Transduction and Targeted Therapy 2021 6:1, vol. 6, no. 1, pp. 1-14, Aug. 2021, doi: 10.1038/s41392-021-00718-w.

65. P. Zhou et al., "A pneumonia outbreak associated with a new coronavirus of probable bat origin," Nature, vol. 579, no. 7798 , pp. 270-273, Mar. 2020, doi: $10.1038 / s 41586-020-2012-7$. 
66. J. Zhao et al., "Antibody responses to SARS-CoV-2 in patients of novel coronavirus disease 2019 Brief Title: Antibody responses in COVID-19 patients," 2020, doi: 10.1101/2020.03.02.20030189.

67. B. Lou et al., "Serology characteristics of SARSCoV-2 infection after exposure and post-symptom onset," European Respiratory Journal, vol. 56, no. 2, Aug. 2020, doi: 10.1183/13993003.00763-2020.

68. R. Krajewski, J. Gołębiowska, S. Makuch, G. Mazur, and S. Agrawal, "Update on serologic testing in COVID-19," Clinica Chimica Acta, vol. 510, pp. 746-750, Nov. 2020, doi: 10.1016/J.CCA.2020.09.015.

69. J. Zhao et al., "Antibody responses to SARS-CoV-2 in patients of novel coronavirus disease 2019," Clinical Infectious Diseases: An Official Publication of the Infectious Diseases Society of America, vol. 71, no. 16, pp. 2027-2034, Oct. 2020, doi: 10.1093/CID/ CIAA344.

70. W. Liu et al., "Two Year Prospective Study of the Humoral Immune Response of Patients with Severe Acute Respiratory Syndrome," The Journal of Infectious Diseases, vol. 193, no. 6, pp. 792-795, Mar. 2006, doi: 10.1086/500469.

71. CK. Li et al., "T Cell Responses to Whole SARS Coronavirus in Humans," The Journal of Immunology, vol. 181, no. 8, pp. 5490-5500, Oct. 2008, doi: 10.4049/ jimmunol.181.8.5490.

72. H. Fehrenbach, "Alveolar epithelial type II cell: Defender of the alveolus revisited," Respiratory Research, vol. 2, no. 1. pp. 33-46, Jan. 15, 2001. doi: $10.1186 / \mathrm{rr} 36$.

73. WE. Wei, Z. Li, CJ. Chiew, SE. Yong, MP. Toh, and VJ. Lee, "Presymptomatic Transmission of SARS-CoV-2 - Singapore, January 23-March 16, 2020," MMWR. Morbidity and Mortality Weekly Report, vol. 69, no. 14, Apr. 2020, doi: 10.15585/mmwr.mm6914e1.

74. World Health Organization, "Situation Report-73 HIGHLIGHTS", doi: 10.3201/eid2606.200239.

75. JB. Aguilar and JB. Gutierrez, "Investigating the Impact of Asymptomatic Carriers on COVID-19 Transmission," medRxiv, p. 2020.03.18.20037994, Mar. 2020, doi: 10.1101/2020.03.18.20037994.

76. SG. Devaraj et al., "Regulation of IRF-3-dependent innate immunity by the papain-like protease domain of the severe acute respiratory syndrome coronavirus," Journal of Biological Chemistry, vol. 282, no. 44, pp. 32208-32221, Nov. 2007, doi: 10.1074/jbc. M704870200

77. M. Frieman, K. Ratia, RE. Johnston, AD. Mesecar, and RS. Baric, "Severe Acute Respiratory Syndrome Coronavirus Papain-Like Protease Ubiquitin-Like Domain and Catalytic Domain Regulate Antagonism of IRF3 and NF-KB Signaling," Journal of Virology, vol. 83, no. 13, pp. 6689-6705, Jul. 2009, doi: 10.1128/jvi.02220-08.

78. IM. Verma, JK. Stevenson, EM. Schwarz, D. van Antwerp, and S. Miyamoto, "Rel/NF-кB/IkB family: Intimate tales of association and dissociation," Genes and Development, vol. 9, no. 22. Cold Spring Harbor Laboratory Press, pp. 2723-2735, Nov. 15, 1995. doi: 10.1101/gad.9.22.2723.

79. D. Wang et al., "Clinical Characteristics of 138 Hospitalized Patients with 2019 Novel Coronavirus-In- fected Pneumonia in Wuhan, China," JAMA - Journal of the American Medical Association, Mar. 2020, doi: 10.1001/jama.2020.1585.

80. F. Chiappelli, "CoViD-19 Immunopathology \& Immunotherapy," Bioinformation, vol. 16, no. 3, pp. 219222, Mar. 2020, doi: 10.6026/97320630016219.

81. C. Qin et al., "Dysregulation of Immune Response in Patients With Coronavirus 2019 (COVID-19) in Wuhan, China," Clinical infectious diseases : an official publication of the Infectious Diseases Society of America, vol. 71 , no. 15 , pp. $762-768$, Jul. 2020, doi: 10.1093/ $\mathrm{cid} / \mathrm{ciaa} 248$.

82. L. Roncati, V. Nasillo, B. Lusenti, and G. Riva, "Signals of Th2 immune response from COVID-19 patients requiring intensive care," Annals of Hematology, vol. 99, no. 6, pp. 1419-1420, Jun. 2020, doi: 10.1007/ s00277-020-04066-7.

83. E. Lozano, M. Dominguez-Villar, V. Kuchroo, and DA. Hafler, "The TIGIT/CD226 Axis Regulates Human T Cell Function," The Journal of Immunology, vol. 188, no. 8, pp. 3869-3875, Apr. 2012, doi: 10.4049/jimmunol.1103627.

84. JL. Riley, "PD-1 signaling in primary T cells," Immunological Reviews, vol. 229, no. 1, pp. 114-125, May 2009, doi: 10.1111/j.1600-065X.2009.00767.x.

85. M. Das, C. Zhu, and VK. Kuchroo, "Tim-3 and its role in regulating anti-tumor immunity," Immunological Reviews, vol. 276, no. 1, pp. 97-111, Mar. 2017, doi: 10.1111/imr.12520.

86. N. Joller et al., "Treg cells expressing the coinhibitory molecule TIGIT selectively inhibit proinflammatory Th1 and Th17 cell responses," Immunity, vol. 40, no. 4, pp. 569-581, Apr. 2014, doi: 10.1016/j. immuni.2014.02.012.

87. SD. Levin et al., "Vstm3 is a member of the CD28 family and an important modulator of T-cell function," European Journal of Immunology, vol. 41, no. 4, pp. 902-915, Apr. 2011, doi: 10.1002/eji.201041136.

88. N. Joller et al., "Cutting Edge: TIGIT Has T Cell-Intrinsic Inhibitory Functions," The Journal of Immunology, vol. 186, no. 3, pp. 1338-1342, Feb. 2011, doi: 10.4049/jimmunol.1003081.

89. KS. Boles et al., "A novel molecular interaction for the adhesion of follicular CD4 T cells to follicular DC," European Journal of Immunology, vol. 39, no. 3, pp. 695-703, 2009, doi: 10.1002/eji.200839116.

90. X. Yu et al., "The surface protein TIGIT suppresses T cell activation by promoting the generation of mature immunoregulatory dendritic cells," Nature Immunology, vol. 10 , no. 1, pp. 48-57, 2009, doi: 10.1038/ ni. 1674 .

91. R. Tanner, B. Villarreal-Ramos, HM. Vordermeier, and $\mathrm{H}$. McShane, "The humoral immune response to BCG vaccination," Frontiers in Immunology, vol. 10, no. JUN. Frontiers Media SA., 2019. doi: 10.3389/ fimmu.2019.01317.

92. A. Salem, A. Nofal, and D. Hosny, "Treatment of common and plane warts in children with topical viable bacillus calmette-guerin," Pediatric Dermatology, vol. 30, no. 1, pp. 60-63, Jan. 2013, doi: 10.1111/ j.1525-1470.2012.01848.x. 
93. HM. Dockrell and SG. Smith, "What have we learnt about BCG vaccination in the last 20 years?," Frontiers in Immunology, vol. 8, no. SEP. Frontiers Media SA., p. 1134, Sep. 13, 2017. doi: 10.3389/fimmu.2017.01134.

94. A. Roy et al., "Effect of BCG vaccination against Mycobacterium tuberculosis infection in children: systematic review and meta-analysis," BMJ, vol. 349, Aug. 2014, doi: 10.1136/BMJ.G4643.

95. LK. Schrager, RC. Harris, and J. Vekemans, "Research and development of new tuberculosis vaccines: a review," F1000Research, vol. 7, 2018, doi: 10.12688/ F1000RESEARCH.16521.2.

96. JM. Achkar, J. Chan, and A. Casadevall, "B cells and antibodies in the defense against Mycobacterium tuberculosis infection," Immunological Reviews, vol. 264 , no. 1 , pp. $167-181$, Mar. 2015 , doi: 10.1111/ imr.12276.

97. C. Zufferey, S. Germano, B. Dutta, N. Ritz, and N. Curtis, "The Contribution of Non-Conventional T Cells and NK Cells in the Mycobacterial-Specific IFNY Response in Bacille Calmette-Guérin (BCG)-Immunized Infants," PLoS ONE, vol. 8, no. 10, pp. 819-835, Oct. 2013, doi: 10.1371/journal.pone.0077334.

98. RM. Brown et al., "Lipoarabinomannan-Reactive Human Secretory Immunoglobulin A Responses Induced by Mucosal Bacille Calmette-Guérin Vaccination," The Journal of Infectious Diseases, vol. 187, no. 3, pp. 513-517, Feb. 2003, doi: 10.1086/368096.

99. R. Monteiro-Maia, MB. Ortigão-de-Sampaio, RT. Pinho, and LRR. Castello-Branco, "Modulation of humoral immune response to oral BCG vaccination by Mycobacterium bovis BCG Moreau Rio de Janeiro (RDJ) in healthy adults," Journal of Immune Based Therapies and Vaccines, vol. 4, no. 1, pp. 1-6, Sep. 2006, doi: 10.1186/1476-8518-4-4/FIGURES/4.

100. I. v. Lyadova, HM. Vordermeier, EB. Eruslanov, S. v. Khaidukov, AS. Apt, and RG. Hewinson, "Intranasal BCG vaccination protects $B A L B / c$ mice against virulent Mycobacterium bovis and accelerates production of IFN-gamma in their lungs," Clinical and Experimental Immunology, vol. 126, no. 2, pp. 274-279, Nov. 2001, doi: 10.1046/j.1365-2249.2001.01667.x.

101. G. Falero-Diaz, S. Challacombe, D. Banerjee, G. Douce, A. Boyd, and J. Ivanyi, "Intranasal vaccination of mice against infection with Mycobacterium tuberculosis.," Vaccine, vol. 18, no. 28, pp. 3223-9, Aug. 2000, doi: 10.1016/s0264-410x(00)00134-1.

102. SR. Rosenthal, JT. Mcenery, and N. Raisys, "Aerogenic BCG vaccination against tuberculosis in animal and human subjects," Journal of Asthma, vol. 5, no. 4, pp. 309-323, 1968, doi: 10.3109/02770906809100348.

103. PA. Darrah et al., "Prevention of tuberculosis in macaques after intravenous BCG immunization," Nature, vol. 577, no. 7788 , pp. 95-102, Jan. 2020, doi: 10.1038/s41586-019-1817-8.

104. S. Mehra et al., "Transcriptional reprogramming in nonhuman primate (Rhesus Macaque) tuberculosis granulomas," PLoS ONE, vol. 5, no. 8, p. e12266, Aug. 2010, doi: 10.1371/journal.pone.0012266.

105. J. Liu, V. Tran, AS. Leung, DC. Alexander, and B. Zhu, "BCG vaccines: Their mechanisms of attenua- tion and impact on safety and protective efficacy," Human Vaccines, vol. 5, no. 2. Taylor \& Francis, pp. 70-78, 2009. doi: 10.4161/hv.5.2.7210.

106. S. Luca and T. Mihaescu, "History of BCG Vaccine," Iasi, 2013.

107. HM. Dockrell and SG. Smith, "What have we learnt about BCG vaccination in the last 20 years?," Frontiers in Immunology, vol. 8, no. SEP. Frontiers Media SA., p. 1134, Sep. 13, 2017. doi: 10.3389/fimmu.2017.01134.

108. PEM. Fine et al., "Environmental mycobacteria in nothern Malawi: Implications for the epidemiology of tuberculosis and leprosy," Epidemiology and Infection, vol. 126, no. 3, pp. 379-387, 2001, doi: 10.1017/ S0950268801005532.

109. RE. Weir et al., "The influence of previous exposure to environmental mycobacteria on the interferon-gamma response to bacille Calmette?Gu rin vaccination in southern England and northern Malawi," Clinical and Experimental Immunology, vol. 146, no. 3, pp. 390-399, Dec. 2006, doi: 10.1111/j.1365-2249 .2006.03222.x.

110. L. Brandt et al., "Failure of the Mycobacterium bovis BCG vaccine: Some species of environmental mycobacteria block multiplication of BCG and induction of protective immunity to tuberculosis," Infection and Immunity, vol. 70 , no. 2, pp. 672-678, Feb. 2002, doi: 10.1128/IAI.70.2.672-678.2002.

111. VL. Petricevich et al., "A single strain of Mycobacterium bovis bacillus Calmette-Guérin (BCG) grown in two different media evokes distinct humoral immune responses in mice," Brazilian Journal of Medical and Biological Research, vol. 34, no. 1, pp. 81-92, 2001, doi: 10.1590/S0100-879X2001000100010.

112. RJW. Arts et al., "Long-term in vitro and in vivo effects of $\mathrm{Y}$-irradiated BCG on innate and adaptive immunity," Journal of Leukocyte Biology, vol. 98, no. 6, pp. 995-1001, Dec. 2015, doi: 10.1189/jlb.4ma0215059r.

113. J. Kleinnijenhuis et al., "Bacille Calmette-Guérin induces NOD2-dependent nonspecific protection from reinfection via epigenetic reprogramming of monocytes," Proceedings of the National Academy of Sciences of the United States of America, vol. 109 , no. 43 , pp. 17537-17542, Oct. 2012, doi: 10.1073/ pnas.1202870109.

114. AM. Minassian, I. Satti, ID. Poulton, J. Meyer, AVS. Hill, and $\mathrm{H}$. McShane, "A human challenge model for Mycobacterium tuberculosis using Mycobacterium bovis bacille Calmette-Guérin," Journal of Infectious Diseases, vol. 205, no. 7, pp. 1035-1042, Apr. 2012, doi: 10.1093/infdis/jis012.

115. R. Tanner, B. Villarreal-Ramos, HM. Vordermeier, and $\mathrm{H}$. McShane, "The humoral immune response to BCG vaccination," Frontiers in Immunology, vol. 10, no. JUN, p. 1317, 2019, doi: 10.3389/ fimmu.2019.01317.

116. P. Ravn, H. Boesen, BK. Pedersen, and P. Andersen, "Human T cell responses induced by vaccination with Mycobacterium bovis bacillus Calmette-Guérin.," The Journal of Immunology, vol. 158, no. 4, 1997.

117. P. Andersen and SHE. Kaufmann, "Novel vaccination strategies against tuberculosis," Cold Spring 
Harbor perspectives in medicine, vol. 4, no. 6, 2014, doi: 10.1101/CSHPERSPECT.A018523.

118. SHE. Kaufmann, "Tuberculosis vaccines: time to think about the next generation," Seminars in immunology, vol. 25, no. 2, pp. 172-181, Apr. 2013, doi: 10.1016/J.SMIM.2013.04.006.

119. I. Sebina et al., "Long-lived memory B-cell responses following BCG vaccination," PloS one, vol. 7, no. 12, Dec. 2012, doi: 10.1371/JOURNAL.PONE.0051381.

120. C. Covián et al., "BCG-Induced Cross-Protection and Development of Trained Immunity: Implication for Vaccine Design," Frontiers in Immunology, vol. 10, p. 2806, Nov. 2019, doi: 10.3389/fimmu.2019.02806.

121. RA. Murray et al., "Bacillus Calmette Guerin vaccination of human newborns induces a specific, functional CD8+ T cell response," Journal of immunology (Baltimore, Md. : 1950), vol. 177, no. 8, pp. 5647-5651, Oct. 2006, doi: 10.4049/JIMMUNOL.177.8.5647.

122. WA. Hanekom, "The immune response to BCG vaccination of newborns," Annals of the New York Academy of Sciences, vol. 1062, pp. 69-78, 2005, doi: 10.1196/ANNALS.1358.010.

123. AP. Soares et al., "Bacillus Calmette-Guérin vaccination of human newborns induces $T$ cells with complex cytokine and phenotypic profiles," Journal of immunology (Baltimore, Md.: 1950), vol. 180, no. 5, pp. 3569-3577, Mar. 2008, doi: 10.4049/ JIMMUNOL.180.5.3569.

124. AP. Soares et al., "Longitudinal changes in CD4(+) T-cell memory responses induced by BCG vaccination of newborns," The Journal of infectious diseases, vol. 207, no. 7, pp. 1084-1094, Apr. 2013, doi: 10.1093/INFDIS/JIS941.

125. H. Su, B. Peng, Z. Zhang, Z. Liu, and Z. Zhang, "The Mycobacterium tuberculosis glycoprotein Rv1016c protein inhibits dendritic cell maturation, and impairs Th1 /Th17 responses during mycobacteria infection," Molecular immunology, vol. 109, pp. 58-70, May 2019, doi: 10.1016/J.MOLIMM.2019.02.021.

126. RM. Steinman and H. Hemmi, "Dendritic cells: Translating innate to adaptive immunity," Current Topics in Microbiology and Immunology, vol. 311, pp. 17-58, 2006, doi: 10.1007/3-540-32636-7_2.

127. CR. Hole et al., "Induction of memory-like dendritic cell responses in vivo," Nature Communications, vol. 10, no. 1, Dec. 2019, doi: 10.1038/s41467-01910486-5.

128. KM. Henkels, K. Frondorf, ME. Gonzalez-Mejia, AL. Doseff, and J. Gomez-Cambronero, "IL-8-induced neutrophil chemotaxis is mediated by Janus kinase 3 (JAK3)," FEBS Letters, vol. 585, no. 1, pp. 159-166, Jan. 2011, doi: 10.1016/j.febslet.2010.11.031.

129. Y. Zhang et al., "Enhanced interleukin-8 release and gene expression in macrophages after exposure to Mycobacterium tuberculosis and its components," Journal of Clinical Investigation, vol. 95, no. 2, pp. 586-592, 1995, doi: 10.1172/JCl117702.

130. T. Chen et al., "Association of Human Antibodies to Arabinomannan With Enhanced Mycobacterial Opsonophagocytosis and Intracellular Growth Reduction," The Journal of infectious diseases, vol. 214 , no. 2 , pp. 300-310, Jul. 2016, doi: 10.1093/ INFDIS/JIW141.

131. A. Yáñez et al., "Detection of a TLR2 agonist by hematopoietic stem and progenitor cells impacts the function of the macrophages they produce," European Journal of Immunology, vol. 43, no. 8, pp. 21142125, Aug. 2013, doi: 10.1002/eji.201343403.

132. JW. WOUT, R. POELL, and R. FURTH, "The Role of BCG/PPD-Activated Macrophages in Resistance against Systemic Candidiasis in Mice," Scandinavian Journal of Immunology, vol. 36, no. 5, pp. 713-720, Nov. 1992, doi: 10.1111/j.1365-3083.1992.tb03132.x.

133. F. Chen et al., "Neutrophils prime a long-lived effector macrophage phenotype that mediates accelerated helminth expulsion," Nature Immunology, vol. 15, no. 10, pp. 938-946, Jan. 2014, doi: 10.1038/ni.2984.

134. E. Kaufmann et al., "BCG Educates Hematopoietic Stem Cells to Generate Protective Innate Immunity against Tuberculosis," Cell, vol. 172, no. 1-2, pp. 176190.e19, Jan. 2018, doi: 10.1016/j.cell.2017.12.031.

135. A. Dolganiuc, C. Garcia, K. Kodys, and G. Szabo, "Distinct toll-like receptor expression in monocytes and T cells in chronic HCV infection," World Journal of Gastroenterology, vol. 12, no. 8, pp. 1198-1204, Feb. 2006, doi: 10.3748/wjg.v12.i8.1198.

136. GF. Black et al., "BCG-induced increase in interferon-gamma response to mycobacterial antigens and efficacy of BCG vaccination in Malawi and the UK: Two randomised controlled studies," Lancet, vol. 359, no. 9315, pp. 1393-1401, Apr. 2002, doi: 10.1016/ S0140-6736(02)08353-8.

137. E. Kindler, V. Thiel, and F. Weber, "Interaction of SARS and MERS Coronaviruses with the Antiviral Interferon Response," in Advances in Virus Research, vol. 96, Academic Press Inc., 2016, pp. 219-243. doi: 10.1016/bs. aivir.2016.08.006.

138. E. Hamano et al., "Polymorphisms of interferoninducible genes OAS-1 and MxA associated with SARS in the Vietnamese population," Biochemical and Biophysical Research Communications, vol. 329 , no. 4, pp. 1234-1239, Apr. 2005, doi: 10.1016/j. bbrc.2005.02.101.

139. A. Kapoor, YH. Fan, and R. Arav-Boger, "Bacterial Muramyl Dipeptide (MDP) Restricts Human Cytomegalovirus Replication via an IFN- $\beta$-Dependent Pathway," Scientific Reports, vol. 6, no. 1, pp. 1-15, Feb. 2016, doi: 10.1038/srep20295.

140. T. Fekete, G. Koncz, B. Szabo, A. Gregus, and E. Rajnavölgyi, "Interferon gamma boosts the nucleotide oligomerization domain 2-mediated signaling pathway in human dendritic cells in an X-linked inhibitor of apoptosis protein and mammalian target of rapamycin-dependent manner," Cellular and Molecular Immunology, vol. 14, no. 4, pp. 380-391, Apr. 2017, doi: 10.1038/cmi.2015.90.

141. SE. Girardin et al., "Nod2 is a general sensor of peptidoglycan through muramyl dipeptide (MDP) detection," J Biol Chem, vol. 278, doi: 10.1074/jbc. c200651200.

142. A. Kapoor, M. Forman, and R. Arav-Boger, "Activation of Nucleotide Oligomerization Domain 2 (NOD2) by Human Cytomegalovirus Initiates Innate Immune 
Responses and Restricts Virus Replication," PLoS ONE, vol. 9, no. 3, p. e92704, Mar. 2014, doi: 10.1371/ journal.pone.0092704.

143. A. Sabbah et al., "Activation of innate immune antiviral responses by Nod2," Nature Immunology, vol. 10, no. 10, pp. 1073-1080, 2009, doi: 10.1038/ni.1782.

144. T. Higashimoto, N. Chan, YK. Lee, and E. Zandi, "Regulation of IKB kinase complex by phosphorylation of $\gamma$-binding domain of IKB kinase $\beta$ by polo-like kinase 1," Journal of Biological Chemistry, vol. 283, no. 51 , pp. $35354-35367$, Dec. 2008 , doi: 10.1074/jbc. M806258200.

145. S. Sharma and PG. Thomas, "The two faces of heterologous immunity: protection or immunopathology," Journal of Leukocyte Biology, vol. 95, no. 3, pp. 405-416, Mar. 2014, doi: 10.1189/jlb.0713386.

146. TP. Primm, CA. Lucero, and JO. Falkinham, "Health Impacts of Environmental Mycobacteria," Clinical Microbiology Reviews, vol. 17, no. 1, pp. 98-106, Jan. 2004, doi: 10.1128/CMR.17.1.98-106.2004.

147. U. Syrbe, S. Jennrich, A. Schottelius, A. Richter, A. Radbruch, and A. Hamann, "Differential regulation of $P$-selectin ligand expression in naive versus memory CD4+ T cells: Evidence for epigenetic regulation of involved glycosyltransferase genes," Blood, vol. 104, no. 10, pp. 3243-3248, Nov. 2004, doi: 10.1182/ blood-2003-09-3047.

148. G. Ristori, D. Faustman, G. Matarese, S. Romano, and M. Salvetti, "Bridging the gap between vaccination with Bacille Calmette-Guérin (BCG) and immunological tolerance: the cases of type 1 diabetes and multiple sclerosis," Current Opinion in Immunology, vol. 55, pp. 89-96, Dec. 2018, doi: 10.1016/j. coi.2018.09.016.

149. RJW. Arts et al., "BCG Vaccination Protects against Experimental Viral Infection in Humans through the Induction of Cytokines Associated with Trained Immunity," Cell Host and Microbe, vol. 23, no. 1, pp. 89-100.e5, Jan. 2018, doi: 10.1016/j. chom. 2017.12.010.

150. HS. Goodridge et al., "Harnessing the beneficial heterologous effects of vaccination," Nature Reviews Immunology, vol. 16, no. 6, pp. 392-400, Jun. 2016, doi: $10.1038 /$ nri.2016.43.

151. KS. Mathurin, GW. Martens, H. Kornfeld, and RM. Welsh, "CD4 T-Cell-Mediated Heterologous Immunity between Mycobacteria and Poxviruses," Journal of Virology, vol. 83, no. 8, pp. 3528-3539, Apr. 2009, doi: 10.1128/jvi.02393-08.

152. AB. Kulkarni, HC. Morse, JR. Bennink, JW. Yewdell, and BR. Murphy, "Immunization of mice with vaccinia virus-M2 recombinant induces epitope-specific and cross-reactive Kd-restricted CD8+ cytotoxic T cells.," Journal of Virology, vol. 67, no. 7, pp. 40864092, 1993, doi: 10.1128/jvi.67.7.4086-4092.1993.

153. K. Koichi, VE. Reyes, RE. Humphreys, and FA. Ennis, "Recognition of disparate HA and NS1 peptides by an $\mathrm{H}-2 \mathrm{Kd}$-restricted, influenza specific CTL clone," Molecular Immunology, vol. 28, no. 1-2, pp. 1-7, Jan. 1991, doi: 10.1016/0161-5890(91)90080-4.

154. N. Shimojo, WL. Maloy, RW. Anderson, WE. Biddison, and JE. Coligan, "Specificity of peptide binding by the HLA-A2.1 molecule.," The Journal of Immunology, vol. 143, no. 9, 1989.

155. RW. Anderson, JR. Bennink, JW. Yewdell, WL. Maloy, and JE. Coligan, "Influenza basic polymerase 2 peptides are recognized by influenza nucleoprotein-specific cytotoxic T lymphocytes," Molecular Immunology, vol. 29, no. 9, pp. 1089-1096, 1992, doi: 10.1016/0161-5890(92)90041-U.

156. LK. Selin, SR. Nahill, and RM. Welsh, "Cross-reactivities in memory cytotoxic t lymphocyte recognition of heterologous viruses," Journal of Experimental Medicine, vol. 179, no. 6, pp. 1933-1943, Jun. 1994, doi: 10.1084/jem.179.6.1933.

157. RM. Welsh and LK. Selin, "No one is naive: The significance of heterologous T-cell immunity," Nature Reviews Immunology, vol. 2, no. 6, pp. 417-426, 2002, doi: 10.1038/nri820.

158. AH. Ellebedy and R. Ahmed, "Re-Engaging CrossReactive Memory B Cells: The Influenza Puzzle," Frontiers in Immunology, vol. 3, no. MAR, p. 53, Mar. 2012, doi: 10.3389/fimmu.2012.00053.

159. R. Levin-Klein and Y. Bergman, "Epigenetic regulation of monoallelic rearrangement (allelic exclusion) of antigen receptor genes," Frontiers in Immunology, vol. 5, no. DEC, 2014, doi: 10.3389/ fimmu.2014.00625.

160. M. Yamashita et al., "Bmi1 regulates memory CD4 T cell survival via repression of the Noxa gene," Journal of Experimental Medicine, vol. 205, no. 5, pp. 11091120, May 2008, doi: 10.1084/jem.20072000.

161. JK. Northrop, RM. Thomas, AD. Wells, and H. Shen, "Epigenetic Remodeling of the IL-2 and IFN - $\gamma$ Loci in Memory CD8 T Cells Is Influenced by CD4 T Cells," The Journal of Immunology, vol. 177, no. 2, pp. 10621069, Jul. 2006, doi: 10.4049/jimmunol.177.2.1062.

162. EN. Kersh et al., "Rapid Demethylation of the IFN -Y Gene Occurs in Memory but Not Naive CD8 T Cells," The Journal of Immunology, vol. 176, no. 7, pp. 40834093, Apr. 2006, doi: 10.4049/jimmunol.176.7.4083.

163. T. Naito and I. Taniuchi, "Roles of repressive epigenetic machinery in lineage decision of T cells," Immunology, vol. 139, no. 2, pp. 151-157, Jun. 2013, doi: 10.1111/imm.12058.

164. PS. de Araujo-Souza, SCH. Hanschke, and JPB. Viola, "Epigenetic control of interferon-gamma expression in CD8 T cells," Journal of Immunology Research, vol. 2015. Hindawi Publishing Corporation, 2015. doi: $10.1155 / 2015 / 849573$.

165. S. Steinfelder et al., "Epigenetic modification of the human CCR6 gene is associated with stable CCR6 expression in T cells," Blood, vol. 117, no. 10, pp. 28392846, Mar. 2011, doi: 10.1182/blood-2010-06-293027.

166. C. Schmidl, L. Hansmann, R. Andreesen, M. Edinger, P. Hoffmann, and M. Rehli, "Epigenetic reprogramming of the RORC locus during in vitro expansion is a distinctive feature of human memory but not naïve Treg," European Journal of Immunology, vol. 41, no. 5, pp. 1491-1498, May 2011, doi: 10.1002/eji.201041067.

167. TA. Fehniger and MA. Caligiuri, "Interleukin 15: Biology and relevance to human disease," Blood, vol. 97, no. 1, pp. 14-32, Jan. 2001, doi: 10.1182/blood. V97.1.14. 
168. B. Agrawal, "Heterologous Immunity: Role in Natural and Vaccine-Induced Resistance to Infections," Frontiers in Immunology, vol. 10, p. 2631, Nov. 2019, doi: 10.3389/fimmu.2019.02631

169. M. Lipsitch, YH. Grad, A. Sette, and S. Crotty, "Crossreactive memory $T$ cells and herd immunity to SARSCoV-2," Nature Reviews Immunology, vol. 20, no. 11, pp. 709-713, Nov. 2020, doi: 10.1038/s41577-02000460-4.

170. HS. Goodridge et al., "Harnessing the beneficial heterologous effects of vaccination," Nature Reviews Immunology, vol. 16, no. 6. Nature Publishing Group, pp. 392-400, Jun. 01, 2016. doi: 10.1038/nri.2016.43.

171. VC. Senterfitt and JW. Shands, "Salmonellosis in Mice Infected with Mycobacterium bovis BCG II. Resistance to Infection," Infection and Immunity, vol. 1, no. 6, pp. 583-586, Jun. 1970.

172. MOC. Ota et al., "Influence of Mycobacterium bovis Bacillus Calmette-Guérin on Antibody and Cytokine Responses to Human Neonatal Vaccination ," The Journal of Immunology, vol. 168, no. 2, pp. 919-925, Jan. 2002, doi: 10.4049/jimmunol.168.2.919.

173. N. Ritz, M. Mui, A. Balloch, and N. Curtis, "Non-specific effect of Bacille Calmette-Guérin vaccine on the immune response to routine immunisations," Vaccine, vol. 31 , no. 30 , pp. 3098-3103, Jun. 2013, doi: 10.1016/j.vaccine.2013.03.059.

174. A. Kiravu et al., "Bacille Calmette-Guérin Vaccine Strain Modulates the Ontogeny of Both Mycobacterial-Specific and Heterologous T Cell Immunity to Vaccination in Infants," Frontiers in Immunology, vol. 10, p. 2307, Oct. 2019, doi: 10.3389/FIMMU.2019.02307/ BIBTEX.

175. LG. Stensballe et al., "BCG Vaccination at Birth and Rate of Hospitalization for Infection Until 15 Months of Age in Danish Children: A Randomized Clinical Multicenter Trial," Journal of the Pediatric Infectious Diseases Society, vol. 8, no. 3, pp. 213-220, Jul. 2019, doi: 10.1093/JPIDS/PIY029.

176. E. Datau, A. Sultana, V. Mandang, and E. Jim, "The Efficacy of Bacillus Calmette-Guérin Vaccinations for The Prevention of Acute Upper Respiratory Tract Infection in The Elderly," 2010.

177. LG. Stensballe et al., "Acute lower respiratory tract infections and respiratory syncytial virus in infants in Guinea-Bissau: A beneficial effect of BCG vaccination for girls: Community based case-control study," Vaccine, vol. 23, no. 10, pp. 1251-1257, Jan. 2005, doi: 10.1016/j.vaccine.2004.09.006.

178. E. Nemes et al., "Prevention of M. tuberculosis Infection with H4:IC31 Vaccine or BCG Revaccination," New England Journal of Medicine, vol. 379, no. 2, pp. 138-149, Jul. 2018, doi: 10.1056/NEJMoa1714021.

179. D. Daulatabad, D. Pandhi, and A. Singal, "BCG vaccine for immunotherapy in warts: is it really safe in a tuberculosis endemic area?," Dermatologic Therapy, vol. 29, no. 3, pp. 168-172, May 2016, doi: 10.1111/ dth. 12336 .
180. I. Podder et al., "Immunotherapy in viral warts with intradermal Bacillus Calmette-Guerin vaccine versus intradermal tuberculin purified protein derivative: A double-blind, randomized controlled trial comparing effectiveness and safety in a tertiary care center in Eastern India," Indian Journal of Dermatology, Venereology, and Leprology, vol. 83, no. 3, p. 411, May 2017, doi: 10.4103/0378-6323.193623.

181. A. Salem, A. Nofal, and D. Hosny, "Treatment of Common and Plane Warts in Children with Topical Viable Bacillus Calmette-Guerin," Pediatric Dermatology, vol. 30 , no. 1 , pp. $60-63$, Jan. 2013 , doi: 10.1111/j.1525-1470.2012.01848.x.

182. L. Jenneke et al., "BCG Vaccination Enhances the Immunogenicity of Subsequent Influenza Vaccination in Healthy Volunteers: A Randomized, Placebo-Controlled Pilot Study," The Journal of Infectious Diseases, vol. 2012, no. 12, pp. 1930-1938, Dec. 2015, doi: https://doi.org/10.1093/infdis/jiv332.

183. VAK. Rathinam and KA. Fitzgerald, "Inflammasomes and anti-viral immunity," Journal of Clinical Immunology, vol. 30, no. 5. Springer, pp. 632-637, Sep. 28, 2010. doi: 10.1007/s10875-010-9431-4.

184. H. Yang and WA. Tompkins, "Nonspecific cytotoxicity of vaccinia-induced peritoneal exudates in hamsters is mediated by Thy-1.2 homologue-positive cells distinct from NK cells and macrophages.," Journal of immunology (Baltimore, Md. : 1950), vol. 131, no. 5, pp. 2545-50, Nov. 1983, Accessed: Apr. 06, 2020. [Online]. Available: http://www.ncbi.nlm.nih. gov/pubmed/6195269

185. PG. Thomas et al., "The Intracellular Sensor NLRP3 Mediates Key Innate and Healing Responses to Influenza A Virus via the Regulation of Caspase-1," Immunity, vol. 30, no. 4, pp. 566-575, Apr. 2009, doi: 10.1016/j.immuni.2009.02.006.

186. "IL1B interleukin 1 beta [Homo sapiens (human)] Gene - NCBI." https://www.ncbi.nlm.nih.gov/gene?D $\mathrm{b}=$ gene\&Cmd=ShowDetailView\&TermToSearch=355 3 (accessed Apr. 06, 2020).

187. J. Kleinnijenhuis et al., "Long-Lasting Effects of BCG Vaccination on Both Heterologous Th1/Th17 Responses and Innate Trained Immunity," Journal of Innate Immunity, vol. 6, no. 2, pp. 152-158, 2014, doi: 10.1159/000355628.

188. N. Curtis, A. Sparrow, T. A. Ghebreyesus, and M. G. Netea, "Considering BCG vaccination to reduce the impact of COVID-19," The Lancet, vol. 0, no. 0, 2020, doi: 10.1016/S0140-6736(20)31025-4.

189. J. Liu, V. Tran, A. S. Leung, D. C. Alexander, and B. Zhu, "BCG vaccines: their mechanisms of attenuation and impact on safety and protective efficacy," Human vaccines, vol. 5, no. 2, pp. 70-78, 2009, doi: 10.4161/HV.5.2.7210.

190. J. M. Chen, S. T. Islam, H. Ren, and J. Liu, "Differential productions of lipid virulence factors among $B C G$ vaccine strains and implications on BCG safety," Vaccine, vol. 25, no. 48, pp. 8114-8122, Nov. 2007, doi: 10.1016/J.VACCINE.2007.09.041. 